
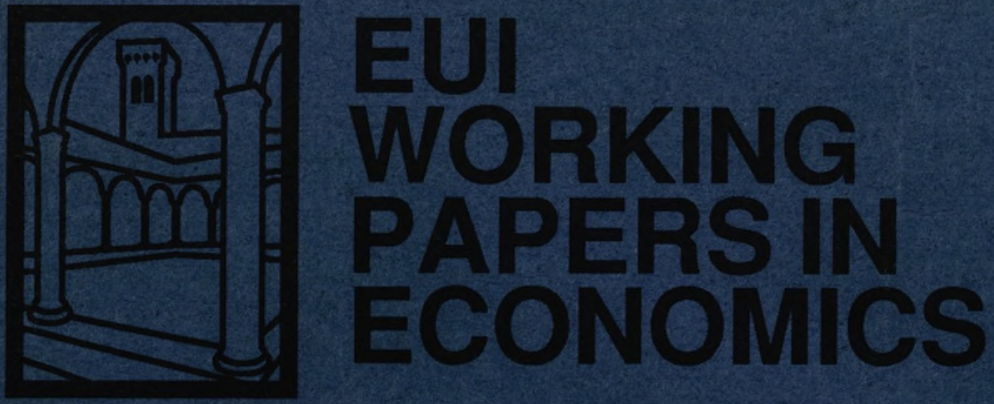

EUI Working Paper ECO No. 91/58

Detrending and Business Cycle Facts

Fabio Canova 
European University Library

||||||||||||||||||||||||||||||||||||||||||||||||||||||||||||||||||||||||||||||||||||||||||||||||||||||||||||||||||||||||||||

30001001356429

Please note

As from January 1990 the EUI Working Paper Series is divided into six sub-series, each sub-series is numbered individually (e.g. EUI Working Paper LA W No. 90/1). 
EUROPEAN UNIVERSITY INSTITUTE, FLORENCE ECONOMICS DEPARTMENT

EUI Working Paper ECO No. 91/58

Detrending and Business Cycle Facts

FABIO CANOVA

BADIA FIESOLANA, SAN DOMENICO (FI) 
All rights reserved.

No part of this paper may be reproduced in any form without permission of the author.

\author{
(C) Fabio Canova \\ Printed in Italy in December 1991 \\ European University Institute \\ Badia Fiesolana \\ I-50016 San Domenico (FI) \\ Italy
}




\title{
Detrending and Business Cycle Facts
}

\author{
Fabio Canova* \\ Department of Economics, Box B, Brown University \\ Providence, RI 02912
}

and

Department of Economics, European University Institute

I-50016 San Domenico di Fiesole, Firenze, Italy

Canova@IFIIUE.bitnet

Telephone: 011-39-55-50921

Fax: 011-39-55-50921-202

This draft: July 20, 1991

\begin{abstract}
This paper examines the business cycle properties of a small set of real US macroeconomic time series using a variety of detrending methods. It is shown that (1) important linear summary statistics of US business cycles vary widely across detrending methods, (2) the qualitative response of consumption, investment, hours and productivity to a typical shock in GNP have, depending on the method used, two types of patterns: one consistent with a Real Business Cycle model and one consistent with a NeoKeynesian labour-hoarding story, (3) the gain function of various detrending filters extract different amounts of information at business cycle frequencies, (4) alternative detrending methods provide different characterizations of business cycle turning point dates and (5) regardless of the detrending method used, the seasonal and the cyclical properties of US business cycles differ both qualitatively and quantitatively.
\end{abstract}

Key words: Detrending, Business Cycles, Seasonality, Filters, Turning Points.

JEL Classification Nos.: 131, 212.

*I would like to thank Tony Braun, Mario Crucini, Frank Diebold, Jane Marrinan, Glen Rudebush and Arnold Zellner for useful comments on an earlier draft of the paper. A version of this paper was presented at the 1990 Winter Meeting of the Econometric Society, Washington, at the 1991 Meetings of the Society for Economic Dynamics and Control, Capri and at the 1991 European Meetings of the Econometric Society, Cambridge. 


\section{Introduction}

Since the influential work of Hodrick and Prescott (1980) it has become increasingly popular to characterize the behavior of macroeconomic variables over the business cycle using a small set of summary statistics (recent examples include Kydland and Prescott (1990), Stock and Watson (1990) and Baxter and Stockman (1989)). The compilation of simple business cycle facts is important for two reasons. First, it gives a coarse summary of the set of complex comovements existing among aggregates in the economy, allows a rough calculation of the magnitude of the fluctuations in economic variables and may guide researchers in choosing leading indicators for economic activity. Second, it provides a set of "regularities" which macroeconomists use as a benchmark to examine the validity of numerical versions of theoretical models.

Any empirical examination of business cycle facts, however, involves the delicate and controversial issue of detrending. There are two problems connected with detrending. The first concerns the lack of a professional consensus on of what constitutes business fluctuations. The second the use of a statistically-based approach vs. an economic-based approach to detrending.

Consider first the issue of what constitutes a business cycle. Business cycle fluctuations are typically identified with deviations from the trend of the process. However, within the empirical literature, there is fundamental disagreement on the properties of the trend and on its relationship with the cyclical component of a series. Therefore different detrending methods embed different concepts of business cycle fluctuations.

In the past the representation and extraction of the secular component of a series was handled in a very simple way. The trend was represented with deterministic polynomial functions of time, assumed to be independent of the cyclical component and extracted using simple regression methods. Hodrick and Prescott (1980) extend this approach by representing the secular component of a series with a smooth, unobservable nonlinear function of time but they still make the fundamental assumption that the secular and the cyclical components of the series are independent. An estimate of the trend of the series can then be obtained using tools developed in the literature on curve fitting (see e.g. Wabha (1980) or Shiller (1984)). Nelson and Plosser's (1982) findings turned around the traditional idea that the variance of the secular component is small relative to the variance of the cyclical component of a series. Based on these results Beveridge and Nelson (1981) produce a decomposition of a series where the secular component is highly variable (exhibits a unit root) and the secular and the cyclical components are perfectly 
correlated. Perron (1989) and Christiano (1989), however, question the evidence reported by Nelson and Plosser. They indicate that the secular component of a series is better represented by a deterministic function of time having structural breaks and suggest an orthogonal representation for the secular and cyclical components of a series. Recent work by Harvey (1985), Watson (1986), Hamilton (1989) propose alternative representations for the components of time series which combine various aspects of the above procedures and suggest different statistical methods for extracting trends.

Since the issue of what is an appropriate representation of the trend can not be solved in small samples and since the choice of the relationship between the cyclical and secular components is arbitrary, statistical based approaches to detrending raise questions about the robustness of certain "facts" reported in the literature. As Singleton (1988, p.372) observes "The stylized facts motivating recent specification of the business cycle models may have been distorted by prefiltering procedures".

The second problem connected with detrending - the question of a statistical versus an economic based decomposition - arises from a standard "measurement without theory" concern. It is often argued that before variables can be selected and facts reported, a theory explaining the mechanism generating economic fluctuations is needed. This point of view has been advocated by those who use economic theory to choose an economic-based decomposition of the actual time series in deriving business cycle regularities (see e.g Singleton (1988), King, Plosser and Rebelo (1989) or Braun (1989)) and also by those who employ economic theory as an organizing principle for time series analysis but use arbitrary filtering procedures to establish stylized business cycle facts (see e.g. Kydland and Prescott (1990) or Stock and Watson (1990)).

Dynamic economic theory, however, does not indicate the type of economic trend that series may display nor the relationship between secular and cyclical fluctuations. In other words, without a set of statistical facts pinning down the properties of the secular component of a time series, the precise economic relationship between the cyclical and secular components is unknown and the choice of any economic-based decomposition arbitrary. This issue is particularly relevant because there has been surprisingly little discussion in the literature on how assumptions about the nature of the secular component affect business cycles facts compiled with an economic-based decomposition (two exceptions are King, Plosser and Rebelo (1989) and King, Plosser, Stock and Watson (1991)), on the possible distortions induced by the use of an arbitrary detrending filter 
(see Cogley (1990) for a discussion of this issue) and on the robustness of reported business cycle regularities (exceptions are Baxter and Stockman (1989) and Baxter (1991)). Because of this circularity, all economic-based decompositions are, at best, attempts to approximate unknown features of a series and therefore subject to specification errors.

Compared to the vastness of the problems raised in this introduction, the focus of the paper is modest. I report the cyclical properties of a small set of series using a number of different detrending methods. The task of the analysis is threefold. First, I want to examine whether certain "stylized facts" are robust across alternative detrending methods. Second, I am interested in studying the ability of various detrending methods to reproduce NBER turning points. The hope is to identify whether there exists a mechanical procedure which is able to broadly replicate features of business cycles as reported by NBER researchers. Third, I hope to shed light on certain "data anomalies" which have motivated recent developments in the real business cycle literature.

The approach of the paper is essentially agnostic. Modern dynamic theory of real economic fluctuations is used only to select the variables of interest for this study. None of the detrending filters employed is believed to be the correct one. Instead, I assume that all procedures are approximations attempting to isolate aspects of the secular and cyclical components of the series. The idea is to organize the information on business cycle fluctuations in a systematic manner in an attempt to identify a set of relationships which is method-free and can be used as a benchmark to guide the development of theoretical macroeconomic research and to statistically justify current NBER dating procedures.

I conduct the exercise with both seasonally adjusted and seasonally nonadjusted data. It is well known that the seasonal filter typically used to adjust macroeconomic variables in the US (the X-11 filter) may induce distortions at frequencies other than the seasonal ones. Also, since each series is adjusted separately using a particular variant of the X-11 filter, it is of interest to examine whether the combination of seasonal adjustment and detrending obscures important relationships across variables. The use of both seasonally adjusted and seasonally nonadjusted data also provides an alternative procedure to determine whether there are regularities common to business and seasonal fluctuations (see Barsky and Miron (1989) and Ghysels (1990)) and whether they are robust when alternative detrending methods are used.

I compare the properties of the cyclical components of six real series (GNP, Consumption, 
Investment, Hours, Productivity and Capital Stock) obtained using nine univariate (HodrickPrescott, Beveridge-Nelson, Linear, Polynomial, Segmented, First Order Differencing, Unobservable Components, Frequency Domain Masking, Hamilton's 2-state Markov chain) and three multivariate (Cointegration, Common Linear and Multivariate Frequency Domain) detrending techniques. For each method I report a set of summary statistics characterizing the linear properties of the data (including sample moments, the short term cross correlations with GNP and the impulse response functions when GNP is shocked) and two statistics describing some of its nonlinear properties (dating of turning points, duration dependence of expansions, contractions and complete cycles). In addition, I describe the properties of the estimated gain function of the detrending filters to examine the distortions introduced by each procedure away from low frequencies.

Antecedents of the type of research carried out here are King and Rebelo (1989), King and Plosser (1989), Baxter and Stockman (1989), Cogley (1990) and Baxter (1991). They demonstrated how the mechanical application of the Hodrick and Prescott filter to series which are either integrated or driven by deterministic trends may induce spurious results, how certain quantitative features of the US business cycle are not robust to the choice of detrending and how one NBER procedure (the Adelmans' test) is weak in discriminating among alternative models.

The paper documents that the second order properties of the estimated cyclical components vary widely across detrending procedures. The qualitative responses of consumption, investment, hours and productivity to a typical shock in GNP exhibit two typical patterns which are consistent with either a technology driven idea of business cycles or with a labor hoarding approach. I also document that most of the detrending procedures induce distortions across frequencies of nonegligible size. None of the methods employed is able to date all business cycle turning points within four quarters of the NBER chronology and most of them fail to recognize at least half of them. Finally, I argue that the seasonal and the business cycle in the US are substantially different. The differences depend, quantitatively, on the detrending procedure and, qualitatively, on the series under consideration.

The analysis of the paper completely ignores the possibility that measurement errors impinge on the raw data. This is potentially a serious problem since the data collected by statistical agencies is massaged in so many ways that spurious results may obtain (see e.g. Wilcox (1988)). The crucial issue for this paper is whether these filtering procedures (which include sectorial and 
temporal aggregations, various adjustments and the use of proxies) induce differing amounts of variability at business cycle or other frequencies on different series. Given the lack of information on the construction of various aggregates, I reluctantly sweep the problem under the rug assuming that measurement errors are negligible and constant across frequencies.

The paper is organized as follows: the next section describes various detrending procedures employed. Section 3 presents a battery of linear and nonlinear summary statistics for the various procedures when seasonally adjusted data are used. Section 4 presents the results for seasonally non-adjusted data. Section 5 compares the properties of the seasonal and the business cycle. Section 6 discusses the implications of the results for existing theoretical work and presents some conclusions.

\section{Alternative Detrending Methods}

This section briefly reviews the procedures used to extract trends from the observable time series. All these methods assume that the trend and the cycle are unobservable but use different assumptions to identify the two components. Also, since only trend and cycle are assumed to exist, all the procedures implicitly assume that either the data has previously been seasonally adjusted or that the seasonal and the cyclical component of the series are lumped together.

Throughout this section I denote the natural logarithm of the observable time series by $y_{t}$, its trend (secular) component by $x_{t}$ and its cyclical component by $c_{t}$.

\subsection{Univariate Procedures}

\subsubsection{Detrending using polynomial functions of time}

This procedure is the simplest and the oldest one. It assumes that the trend and the cyclical component of the $(\log )$ of each series are uncorrelated and that the secular component is a deterministic process which can be approximated by simple polynomial functions of time. These assumptions imply a model for $y_{t}$ of the form

$$
\begin{gathered}
y_{t}=x_{t}+c_{t} \\
x_{t}=a+\sum_{j}^{q} b_{1 j} f_{j}\left(t-t_{0}\right) \quad \text { if } t \leq \bar{t}
\end{gathered}
$$




$$
x_{t}=a+\sum_{j}^{q} b_{2 j} f_{j}\left(t-t_{1}\right) \quad \text { if } \bar{t}+1 \leq t \leq T
$$

where $\mathrm{q}$ is typically chosen to be small and where $t_{0}$ and $t_{1}$ are given points in time, scaling the origin of the trend. In (2), I allow for the possibility of a structural break at a known time $\bar{t}$ in the secular component of the series. The trend of the series can be estimated by fitting $y_{t}$ to a constant and to scaled polynomial functions of time using least squares and by taking the predicted value of the regression (see e.g. Anderson (1971)) An estimate of the cyclical component is $\hat{c}_{t}=y_{t}-\hat{x}_{t}$. I present results obtained when $f_{j}\left(t-t_{0}\right)=t-t_{0}$ and $\bar{t}=T$ (LT in the tables), when $f_{j}\left(t-t_{0}\right)=t-t_{0}+\left(t-t_{0}\right)^{2}+\log \left(t-t_{0}\right)$ and $\bar{t}=T$ (POLY in the tables) and when $f_{j}\left(t-t_{0}\right)=t-t_{0}, f_{j}\left(t-t_{1}\right)=t-t_{1}$ and $\bar{t}=1973,3$ (SEGM in the tables).

\subsubsection{Detrending using First Order Differences}

The basic assumptions of the first order differencing procedure (RW) are that the secular component of the series is a random walk with no drift, the cyclical component is stationary and that the two components are uncorrelated. Under these assumptions $y_{t}$ has a unit root which is entirely due to the secular component of the series. Therefore $y_{t}$ can be represented as:

$$
y_{t}=y_{t-1}+\epsilon_{t}
$$

and an estimate of $c_{t}$ is obtained as $\hat{c}_{t}=y_{t}-y_{t-1}$.

\subsubsection{Detrending using Hodrick-Prescott's filter}

The two main hypotheses underlying Hodrick and Prescott's (1980) decomposition are that the trend is stochastic but moves smoothly over time, and that the secular and the cyclical components are independent. The assumption that the trend is smooth is imposed by assuming that the sum of squares of the second differences of $x_{t}$ is small. This penalty function is widely used in the literature on curve fitting (see e.g. Kimeldorf and Wabha (1970), Shiller (1984), Wabha (1980) ). An estimate $\hat{x}_{t}$ of the secular component is obtained by minimizing:

$$
\min _{\left[x_{t}\right]_{t=1}^{T}}\left[\sum_{t=1}^{T} c_{t}^{2}+\lambda \sum_{t=1}^{T}\left(\left(x_{t}-x_{t-1}\right)-\left(x_{t-1}-x_{t-2}\right)\right)\right]^{2} \quad \lambda>0
$$

where $T$ is the sample size and $\lambda$ is a parameter that penalizes the variability of trend. As the value of $\lambda$ increases, the penalty imposed for large fluctuations in the secular component 
increases and the path for $\hat{x}_{t}$ becomes smoother. The optimal value of $\lambda$ is series dependent and can be obtained by casting the minimization problem into a signal extraction-prediction error decomposition framework. Using this framework it can be shown that when $\lambda=\frac{\sigma_{1}^{2}}{\sigma_{2}^{2}}$, where $\sigma_{1}$ and $\sigma_{2}$ are the standard errors of the trend and of the cyclical component of the series, $\hat{x}_{t}$ is the maximum likelihood estimator of the secular component of the series ${ }^{1}$.

Hodrick and Prescott do not estimate $\lambda$. Instead a-priori they choose $\lambda$ based on the assumption that the standard deviation of the cyclical component $\sigma_{1}$ is forty times the standard deviation of the secular component $\sigma_{2}$ and use this value of $\lambda$ for all series. This assumption about the relative magnitude the shocks is debatable on two grounds. First, Nelson and Plosser (1982) estimate $\lambda$ to be in the range $\left[\frac{1}{6}, 1\right]$ for most of the series they examine, a range far from the value of 40 assumed by Hodrick and Prescott. Second, since different economic aggregates possess different degrees of smoothness, the application of the Hodrick-Prescott filter with a uniformly standardized value of $\lambda$ may distort features of summary correlations. I will investigate this possibility by experimenting with three measures of the smoothness parameter: one obtained estimating $\lambda$ separately for each series by maximum likelihood (HPOPT in the tables), one by assuming that the relative variability of the components is 2 (HP4 in the tables) and another obtained by assuming that the relative variability of the components is 40 (HP1600 in the tables).

The rest of the procedure involves the computation of $\mathrm{T}$ first-order conditions with respect to $x_{1}, x_{2}, \cdots, x_{T}$ and the solution of a system of $\mathrm{T}$ linear simultaneous equations in $\mathrm{T}$ unknowns, of the form $\hat{x}_{t}=A y_{t}$. An estimate of the cyclical component is obtained as $\hat{c}_{t}=y_{t}-\hat{x}_{t}$.

The ability of the HP filter to induce stationarity in trending series has been examined by King and Rebelo (1989). Some of the properties of the HP1600 filter when $T \rightarrow \infty$ and the penalty function is two-sided have been highlighted by Cogley (1990).

\footnotetext{
${ }^{1}$ To get this result assume that the cyclical component and the second difference of the trend are identically and independently distributed normal variates with zero means and variances $\sigma_{1}^{2}$ and $\sigma_{2}^{2}$, respectively. The conditional expectations of the path $\left(x_{t}\right)_{t=1}^{T}$ is obtained by minimizing $\left[\sigma_{1}^{-2} \sum_{t=1}^{T} c_{t}^{2}+\sigma_{2}^{-2} \sum_{t=1}^{T}\left[\left(x_{t}-x_{t-1}\right)-\left(x_{t-1}-x_{t-2}\right)\right]^{2}\right]$ with respect to $x_{t}$ and with $x_{0}$ and $x_{-1}$ as initial conditions. The minimand of the problem with respect to $x_{t}$ is proportional to the negative of the log-likelihood. Therefore, the resulting path $\tilde{x_{t}}, 1 \leq t \leq T$ obtained using this programming problem is the maximum likelihood estimate of $x_{t}, 1 \leq t \leq T$ based on the observations of $y_{t}$ up to period $T$. Using standard signal extraction arguments (see e.g. Sargent (1986)) the result follows.
} 


\subsubsection{Detrending using Beveridge-Nelson's procedure}

Beveridge and Nelson's (1981) detrending procedure finds its roots in the provocative work of Nelson and Plosser (1982). The key identifying assumption of this procedure is that the cyclical component of the series is stationary while the secular component accounts for its nonstationary behavior. Let $w_{t}=(1-\ell) y_{t}$ and assume that $w_{t}$ is a stationary ARMA process of the form

$$
\phi(\ell) w_{t}=\mu^{\prime}+\theta(\ell) \varepsilon_{t} \quad \varepsilon_{t} \sim \text { i.i.d. }\left(0, \sigma_{\varepsilon}^{2}\right)
$$

where $\phi(\ell)$ and $\theta(\ell)$ are polynomials in the lag operator of order $p$ and $q$ respectively and where the roots of $\phi(z)=0$ lie outside the unit circle. Let the moving average representation for $w_{t}$ be:

$$
w_{t}=\mu+\gamma(\ell) \varepsilon_{t},
$$

where $\mu=\frac{\mu^{\prime}}{\phi(1)}$ and $\gamma(\ell)=\phi^{-1}(\ell) \theta(\ell)$ and $\phi(1)=1-\sum_{j=1}^{p-1} \phi_{j}$.

Beveridge and Nelson show that, under the assumptions made, the secular component of a series can be defined as the long run forecast of $y_{t}$ adjusted for its mean rate of change $k \mu$; i.e

$$
\begin{gathered}
x_{t} \equiv \hat{y}_{t}(k)-k \mu, \\
\hat{y}_{t}(k)=y_{t}+\hat{w}_{t}(1)+\cdots+\hat{w}_{t}(k)
\end{gathered}
$$

with $\hat{w}_{t}(i)=E_{t}\left(w_{t+i} \mid y_{t}, y_{t-1}, \cdots\right)=\left(\sum_{i=1}^{k} \gamma_{i}\right) \varepsilon_{t}+\left(\sum_{i=2}^{k+1} \gamma_{i}\right) \varepsilon_{t-1}+\cdots, \quad i=i, \ldots k$.

For $k$ sufficiently large, the first term of the right hand side of $(6)$ is approximately constant, the secular component $x_{t}$ is the value the series would have taken if it were on the long-run path. Therefore, letting $k$ go to infinity (6)-(7) collapse to:

$$
x_{t}-x_{t-1}=\mu+\left(\sum_{i=1}^{\infty} \gamma_{i}\right) \varepsilon_{t}, \quad \lambda_{0} \equiv 1
$$

The cyclical component of the series is defined by

$$
\begin{aligned}
c_{t} & =\hat{w}_{t}(1)+\cdots+\hat{w}_{t}(k)-k \mu \\
& =\sum_{j=1}^{\infty}\left(\sum_{i=j+1}^{\infty} \gamma_{i}\right) \varepsilon_{t-j}=\chi(\ell) \varepsilon_{t}
\end{aligned}
$$

Two characteristics of this decomposition should be noted. First, since the two components are driven by the same shock, this decomposition has the remarkable property that the secular and the cyclical components are perfectly correlated. Second, since this procedure relies on 
estimates of the $\gamma$ 's and on forecasts $w_{t}(k)$ obtained from an ARIMA model, the problems inherent in ARIMA specifications are carried over to this detrending method. For example, as Christiano and Eichenbaum (1990) and others have recently pointed out, there are several ARIMA models which fit the sample autocorrelations of a data set fairly well. However, since different ARIMA models having the same short run properties may have very different long run features, alternative model specifications may lead to very different decompositions of the series into trend and cycle. Here I present results obtained using $\theta(\ell)=1 \forall \ell$, five lags for $\phi(\ell)$ and using the quick computational approach suggested by Coddington and Wathers (1987) (BN in the tables) ${ }^{2}$.

\subsubsection{Detrending using an Unobserved Components Model}

The unobserved components model, proposed by Harvey (1985) and Watson (1986) among others, is an alternative to ARIMA based procedures for decomposing aggregate series into secular and cyclical components. Unobserved components (UC) models are usually cast in a state space framework and the stochastic properties of the secular and of the cyclical components of a time series are specified to have very simple features. The key identifying assumptions of this procedure are that the secular component follows a random walk with drift and that the cyclical component is a stationary finite order AR process. The measurement equation is given by

$$
y_{t}=x_{t}+c_{t}+\epsilon_{t}, \quad t=1, \ldots T,
$$

where $\epsilon \sim N\left(0, \sigma^{2}\right)$ for all $t$ and $E\left(\epsilon_{t} \epsilon_{t-i}\right)=0$ for $i \neq 0$. The transition equations for $x_{t}$ and $c_{t}$ are

$$
\begin{aligned}
x_{t} & =x_{t-1}+\delta+u_{t}, \\
c_{t} & =\phi(\ell) c_{t-1}+\nu_{t}
\end{aligned}
$$

where $\delta$ is a constant and the roots of $\phi(z)=0$ lie outside unit circle. The stochastic properties of $x_{t}$ and of $c_{t}$ are fully characterized by the assumption that the distribution of $u_{t}$ and $\nu_{t}$ are jointly normal with covariance matrix $\Sigma$ and by the fact that $\epsilon_{t}$ is uncorrelated with $u_{t}$ and $\nu_{t}$. To incorporate Nelson and Plosser's (1982) idea that $x_{t}$ and $c_{t}$ may be correlated I assume

\footnotetext{
${ }^{2}$ Sensitivity results obtained with alternative specifications for $\theta(\ell)$ and $\phi(\ell)$ are available upon request. The results vary considerably with the choice of $\theta$ and $\phi$ both in terms of the magnitude of the standard errors and in terms of the relative size of many of the summary statistics presented.
} 
that the contemporaneous correlation between $u_{t}$ and $\nu_{t}, \sigma_{u, \nu}$, is different than zero ${ }^{3}$. The parameters $\beta=\left(\sigma^{2}, \sigma_{u}^{2}, \sigma_{\nu}^{2}, \sigma_{u, \nu}, \delta, \phi_{j} j=1, \ldots, p\right)$ of the model can be estimated using the prediction error decomposition of the likelihood (see, e.g. Harvey (1985)) ${ }^{4}$. To simplify the procedure I use approximate maximum likelihood estimates for the $\theta$ 's using the autocovariances of $w_{t}=(1-\ell) y_{t}$ (see Carvalho, Grether and Nerlove (1979)).

For computational purposes transform the transition equations into a $\mathrm{AR}(1)$ companion form

$$
\alpha_{t}=B \alpha_{t-1}+\xi_{t}
$$

where $\alpha_{t}=\left[x_{t}, c_{t}, \ldots c_{t-q}, 1\right]^{\prime}, B$ is a matrix of coefficients and $\xi_{t}=\left[u_{t}, \nu_{t}, 0, \ldots, 0\right]^{\prime}$. Thus the measurement equation reduces to

$$
y_{t}=z^{\prime} \alpha_{t}+\epsilon_{t},
$$

where $z^{\prime}=[1,1,1, \ldots, 0]$. Given initial conditions (typically a zero mean and a diagonal covariance matrix with large but finite elements (see e.g. Harvey and Todd (1983)) and an estimate of $\beta$, Kalman filter iterations produce recursive estimates of the state vector $\alpha_{t}$. The first and second elements of $\alpha_{t}$ then provide recursive estimates of $x_{t}$ and $c_{t}$. I report results obtained when $\phi(\ell)$ is a second order polynomial (UC in the tables) ${ }^{5}$. Finally, since in (10) we distinguish between cyclical and irregular fluctuations, the estimated variability of the cyclical compcnent for each series is likely to be smaller than the variability of the cyclical component estimated with other methods.

\subsubsection{Detrending using frequency domain methods}

The frequency domain procedure employed here draws from Sims (1974). I assume that the cyclical and secular components of the series are independent, that the secular component has most of its power concentrated in a low frequency band of the spectrum and that away from zero the power of the secular component decays very fast. This identification procedure does not restrict the trend to be either deterministic or stochastic and allows for changes in the trend

\footnotetext{
${ }^{3}$ An alternative way of representing the interrelation of two components appears in Watson (1986), where the $\nu_{t}$ is a linear combination of $u_{t}$ and another disturbance term.

${ }^{4} \mathrm{~A}$ more precise estimate of the $\theta$ 's can be obtained using a smoothing algorithm which revises recursive estimates of the parameters using the information contained in the entire sample. Significant reductions in residuals of observed series can be obtained using a smoothing algorithm.

${ }^{5}$ Results obtained with other specifications of $\phi(\ell)$ are very similar and not reported.
} 
over time as long as the changes are not too frequent. The secular component can be recovered from $y_{t}$ using

$$
a(\omega) F_{y}(\omega)=F_{x}(\omega)
$$

where $a(\omega)$ is a "low" pass filter and $F_{y}(\omega)$ and $F_{x}(\omega)$ are the Fourier transforms of $y_{t}$ and $x_{t}$. In the time domain it can be shown (see e.g. Priestley, 1981, p.275) that the polynominal $a(\ell)$, the inverse Fourier transform of $a(\omega)$, has the form:

$$
a(\ell)=\frac{\sin \left(\omega_{2} \ell\right)-\sin \left(\omega_{1} \ell\right)}{\pi \ell}
$$

where $\omega_{1}$ and $\omega_{2}$ are the upper and lower limits of the frequency band where the secular component has all its power. The cyclical component of $y_{t}$ can be estimated using $(1-a(\ell)) y_{t}$. The key to this procedure is the correct specification of the upper and lower limits of the filter. Following the NBER taxonomy which describes business cycle fluctuations as those cycles with 3-5 years periodicity and the conventional wisdom that no complete cycle has exceeded 8 years in length, I chose $\omega_{1}=0$ and $\omega_{2}=\frac{\pi}{15}{ }^{6}$. This identifying restriction implies that the power of the spectrum of $y_{t}$ corresponding to cycles with length less that 30 quarters is entirely due to the cyclical component $c_{t}$ (FD1 in the tables). Since the filter leaves a considerable amount of undesirable high frequency variability, I also consider a decomposition of $y_{t}$ as in (10)) where $\epsilon_{t}$ is identified by the assumption that it has most of its power located in a high frequency band of the spectrum. In this case the cyclical component of the series is obtained with a filter which, in addition to eliminating all cycles with period greater than thirty quarters, wipes out all cycles with period less than six quarters. This is achieved by choosing $a(\omega)$ to be:

$$
\begin{aligned}
a(\omega) & =1 & & \text { if } \omega \varepsilon\left[\omega_{1}, \omega_{2}\right] \cup\left[\omega_{3}, \omega_{4}\right] \\
& =0 & & \text { otherwise }
\end{aligned}
$$

where $\omega_{1}=0, \omega_{2}=\frac{\pi}{15}$ and $\omega_{3}=\frac{\pi}{3}$ and $\omega_{4}=\pi$ (FD2 in the tables).

\subsubsection{Detrending using Hamilton's 2-State Markov Chain}

Hamilton (1989) pioneered a modelling approach to nonstationary time series where the secular component of the series is assumed to be subject to binomial random shifts. The key identifying

\footnotetext{
${ }^{6}$ Note that since the spectrum is symmetric around the origin, this choice of filter wipes out all the power in the band $\left(-\frac{\pi}{15}, \frac{\pi}{15}\right)$.
} 
assumptions of this procedure are that the secular and cyclical components of the log of the series are independent and that both components are nonstationary. The model has the form of equation (1) where $x_{t}$ and $c_{t}$ are given by:

$$
\begin{aligned}
x_{t} & =a_{0}+a_{1} s_{t}+x_{t-1} \\
s_{t} & =(1-q)+\lambda s_{t-1}+v_{t} \\
c_{t} & =c_{t-1}+\phi(\ell)\left(c_{t-1}-c_{t-2}\right)+\epsilon_{t}
\end{aligned}
$$

where $s_{t}$ is a two state Markov chain with AR representation (16), whose transition matrix P has diagonal elements $p, q ; \lambda=p+q-1, \phi(\ell)$ is a polynomial in the lag operator of order $r$ with all roots outside the unit circle and $\epsilon_{t} \sim$ iid $\mathcal{N}\left(0, \sigma_{\epsilon}^{2}\right)$. By construction $\epsilon_{t}$ and $s_{t}$ are uncorrelated. The above structure implies that given an initial condition $x_{0}$ and estimates of $a_{0}, a_{1}$ and $s_{t}$, an estimate of the cyclical component of the series can be obtained from (15)-(17). Parameter estimates are obtained here using Hamilton's EM algorithm.

Hamilton's detrending filter introduces several novelties. First, contrary to previous procedures, Hamilton assumes that the cyclical component is nonstationary (see Lam (1990) for a version of the model where the cyclical component is stationary). Second, although the trend is characterized by a unit root, its shifts are drawn from a binomial rather than from a continuous distribution. Finally, the procedure includes as special cases polynomial trends when $s_{t}$ is constant and segmented trends model when $s_{t}$ assumes a different value in each of two subsamples.

\subsection{Multivariate Procedures}

\subsubsection{Detrending using Common Deterministic Trends}

King, Plosser and Rebelo (1989) present a neoclassical model of capital accumulation enlarged to include labor supply choices where there is deterministic labor augmenting technical progress. Their model implies that all the endogenous variables have a common deterministic trend (the growth rate of labor augmenting technical progress) and that fluctuations around the trend are all of a transitory nature. Each time series is therefore generated by a model like (1) where the secular and cyclical components are independent and where $x_{t}$ is common to all series and given by

$$
x_{t}=x_{0}+\delta t
$$


where $\delta$ is the growth rate of technological progress. Because total hours are bounded by the endowment of the economy, it must be the case that the trend in hours per-capita is zero. King, Plosser and Rebelo use a value of $\delta=.4 \%$ and detrend all the series using the resulting $x_{t}$. I follow their procedure and construct a deterministic trend which is common to all series. For the data set employed here the estimated value of $\delta$ is $.7 \%^{7}$. $x_{0}$ is chosen to be an estimate of the unconditional mean of each series. Since hours here are measured in absolute terms I detrended using the growth rate of population (about $.3 \%$ per quarter over the sample $55,3-86,3$ ).

\subsubsection{Detrending using a Cointegration Method}

King, Plosser, Stock and Watson (1987) propose a theoretical model where the long run properties of the endogenous real variables are driven by the same nonstationary technological shock. The corresponding statistical common trend representation developed in Stock and Watson (1988) implies that series have a common trend if there exists a cointegrating vector which can make all series simultaneously stationary. This approach produces as a by-product a model driven decomposition of the series into secular (nonstationary) and cyclical (stationary) components which is the multivariate counterpart of the method proposed by Beveridge and Nelson. As in that framework, the two components are perfectly correlated because they are driven by the same shocks. Let $w_{t}$ be an $n \times 1$ vector of time series where $w_{t}=(1-\ell) y_{t}$ has moving average representation:

$$
w_{t}=\delta+C(\ell) \epsilon_{t}+B(\ell) z_{t}
$$

where $\alpha^{\prime} C(1)=0$ and where $\epsilon_{t}=G^{\frac{1}{2}} v_{t}$ with $v_{t} \sim$ iid $(0, G)$. Expanding (19) we have:

$$
y_{t}=y_{0}+\delta t+C(1) \zeta_{t}+D(\ell) \epsilon_{t}
$$

where $D_{j}=-\sum_{i=1+j}^{\infty} C_{i}$ and $\zeta_{t}=\sum_{s=1}^{t} \epsilon_{s}$. Stock and Watson show that (20) implies that:

$$
\begin{gathered}
x_{t}=y_{0}+A \tau_{t}=y_{0}+\delta t+C(1) \zeta_{t} \\
c_{t}=D(\ell) \epsilon_{t}
\end{gathered}
$$

where $A$ is a $n \times k$ vector, $\tau_{t}=\mu+\tau_{t-1}+\eta_{t}, \eta_{t}$ is a serially uncorrelated random noise and $\operatorname{dim}\left(\tau_{t}\right)=k \leq n$. Rather than testing whether there is a cointegrating vector $z_{t}$ for the system,

\footnotetext{
${ }^{7}$ The major reason for the discrepancy between King, Plosser and Rebelo and my estimate are that they employ a different sample and they do not include the capital stock in the calculation of their common trend.
} 
I work directly with the AR version of (19). That is, I estimate a vector error correction model (VECM) and use one lag of three cointegrating vectors (GNP/consumption, GNP/investment, $\mathrm{GNP} /$ capital) to obtain estimates of $\delta, C(\ell)$ and $\epsilon_{t}$. Then using (22) I compute an estimate of the transitory component of the model by taking $\hat{c}_{t}=y_{t}-y_{0}-\hat{\delta} t-\hat{C}(1) \hat{\zeta}_{t}$.

As in the Beveridge-Nelson decomposition, estimates of the secular and transitory components differ for different specifications of the VECM model (both in terms of the number of variables and in terms of the choice of lag length). Here I present the results obtained using five lags for each variable and including all variables in the system (COIN in the tables) ${ }^{8}$.

\subsubsection{Detrending Using an Alternative Common Trend Assumption}

The two previous subsections presented multivariate detrending procedures which assume that although each series is trending (deterministically or stochastically), some linear combination of them does not have any trend. Here I describe a multivariate frequency domain procedure which accomplishes the same objective without making assumptions on the nature (stationary or nonstationary) of the trend. The idea is to extract the part of the secular component which is common to all series using an index model. The approach used to implement this idea is similar to the one employed by Stock and Watson (1989). I assume that in the low frequencies of the spectrum there exists a one dimensional process (a secular component) which is common to all series. This index is characterized by the property that it has all its power at low frequencies and that away from zero it decays very fast. The model has the multivariate representation:

$$
y_{t}=x_{t}+c_{t}
$$

where $y_{t}$ is a $6 \times 1$ vector, $x_{t}=A z_{t}$ and $z_{t}$ is a one dimensional process with $0<S_{z}(\omega)<$ $M, \forall \omega \varepsilon[\bar{\omega}, \pi]$ where $S_{z}(\omega)$ is the spectral density of $z_{t}$ and $M$ is a small number and $x_{t}$ and $c_{t}$ are independent. An estimate of $x_{t}$ is obtained using the prediction error decomposition of the likelihood (as in the UC procedure) and $\hat{c}_{t}$ is obtained from (23) (MFD in the tables). Compared with previous multivariate procedures, this approach has the advantage of making the idea of a common trend operative without imposing a-priori assumptions on the nature of the trend.

\footnotetext{
${ }^{8}$ Results for alternative specifications are available on request.
} 


\section{$3 \quad$ Results using Seasonally Adjusted Data}

This section presents results obtained using seasonally adjusted U.S. data. Quarterly values for the period 55,3-86,3 for five series (GNP, Consumption, Investment, Hours, Wage Compensation) are obtained from the Citibase tape. GNP measures Real Gross National Product in 1982 dollars (Citibase name: GNP82), Consumption measures consumption expenditure by domestic residents on nondurables and services in 1982 dollars (Citibase names: GSC82 and GCN82), investment measures total fixed investments in plants and equipment plus consumer durables in 1982 dollars (Citibase names: GINPD82 and GCD82), hours measures the total number of hours of labor input as reported by the establishment survey data (Citibase name:LPMHU) and the wage series measures total compensation of nonagricultural employees (Citibase name: GCOMP). A quarterly series for the capital stock is constructed using the net capital stock (residential and nonresidential) for 1954,4, the quarterly series for investment and a depreciation rate of $2.5 \%$ per quarter. Since the time series properties of the wage and of a productivity series (constructed as the ratio GNP/Hours) are very similar, I will refer to the wage series as wage or productivity interchangeably ${ }^{9}$.

Time plots for the log of the data, their estimated log spectrum and the estimated coherence of each series with GNP appear in figure 1. Plots of the estimates of the cyclical component of GNP obtained using different detrending methods appear in figure 2. Shaded areas in the time plots indicate recessions according to NBER chronology. Shaded areas in the plots of estimated $\log$ spectrum and coherence indicate business cycle frequencies (cycles with periods of oscillation between six and thirty quarters).

\subsection{The Plots}

Several features of the time plots deserve comment. First, all series exhibit upward movements after the removal of an exponential trend. Second, the spectral densities of the six variables look alike, indicating the existence of common stochastic patterns across series (see Canova (1991) for a definition of common patterns). This impression is confirmed by the plots of the coherences with GNP which show moderately high levels of correlations at business cycle frequencies.

\footnotetext{
${ }^{9}$ The major difference with data used by the real business cycle literature is in the capital stock series. For example, Kydland and Prescott (1990) do not include residential capital stock in their series. I also examined alternative measures of consumption (nondurables, total), of hours (household survey) and of wage (output per man-hour in manufacturing). The results are somewhat different and appear in the appendix.
} 
The plots of the estimated cyclical component of GNP indicate that detrending methods that impose a random walk on the secular component of the series (RW, BN, UC, HAMIL and COIN) induce lower variability in the resulting cyclical component. Among these methods, the Hamilton filter leaves, as expected, much higher variability in the cyclical component than the others. However, since some decompositions use (1) while others use (10) as the basic model, differences across methods may be due to the alternative ways the procedures handle the irregular component of the series.

The cyclical components of GNP obtained with linear, polynomial and segmented filters look quite similar but have a slightly different mean value. The cyclical components of GNP obtained with BN, RW and HP4 filters also resemble each other. In addition, the optimal HP filter and FD1 produce a cyclical component of GNP similar to the standard HP1600 filter. Finally, the three multivariate detrending methods produce cyclical component of GNP which are similar to each other but very different from those obtained using univariate methods.

The plots of the cyclical components of the other five variables with the 15 different detrending methods (appearing in the appendix for reason of space) have essentially the same features. The wage series seems to be the exception. Depending on the detrending methods, its cyclical component may display very short or very long swings. Among detrending procedures, the Hamilton filter produces cyclical components that are very different from all the others. This is evident especially for the consumption and the wage series where the standard errors on the estimated parameters are so large that the two growth states are indistinguishable.

Finally, the trends of the series are largely similar across detrending methods. The trend for investment is the most rugged and its variability is large relative to other series when HP4, UC, RW or HAMIL filters are used.

\subsection{Summary Statistics}

In this section I examine a few moments of the distribution of the detrended data (the absolute variability of GNP, the variability of five series relative to output and the coefficients of skewness and kurtosis for all series) and the short term correlations of each series with GNP. In the next subsections I look in more detail at the correlation properties of the data.

Table 1 presents the absolute standard errors of the log of detrended GNP and the relative standard errors of the other five variables (in percentage of GNP standard errors). Table 2 presents cross correlations at lags $(-1,0,1)$. In both tables a "*" indicates that the statistic in the 
cell significantly differs (at the $5 \%$ significance) from the corresponding statistic obtained with the HP1600 filter ${ }^{10}$. Table 3 displays the estimated coefficients of skewness and table 4 contains the estimated coefficients of kurtosis. A "*" in these two tables indicates that the statistic in the cell significantly differs from the statistic which would appear if the detrended series under consideration had a normal distribution (these are equal to 0 and 3 , respectively) ${ }^{11}$.

\subsubsection{Standard Errors and Cross Correlations}

The standard errors of the detrended series vary greatly across detrending methods. The absolute variability of the cyclical component of GNP is smallest for UC (.38) and for HP4 (.55) and largest for MFD (5.65). HP1600 generates approximately the median value. The range of relative variabilities is large as well. For example, the variability of consumption is between $34 \%$ and $153 \%$ of the variability of GNP while the variability of investment ranges between $97 \%$ to $672 \%$ of the variability of GNP. Hours can be half as volatile as GNP (using LT and BN filters) or up to two times more volatile than GNP (when a HAMIL filter is used) In turn, the relative variability of productivity to GNP varies between $78 \%$ and $336 \%$, with the HP1600 filter producing the lowest relative variability. Finally, hours can be much less or much more volatile than productivity (range $18 \%$ to $178 \%$ ) (see also Baxter (1991). These last two findings are particularly relevant since the relative volatility of productivity has been the object of much debate in the literature. They imply that even qualitative statements like "Over the typical business cycle, employment varies substantially while determinants of the labor supply - the real wage and the real interest rate - vary only slightly" (Mankiw $(1989$, p.86)) or that the variability of productivity is less than the variability of output (Prescott (1990, table 1)) represent a potentially misleading characterizations of US business cycles.

In general, the relative variabilities of the series filtered with HP1600 are among the lowest across detrending methods. The relative standard errors obtained using an optimal value of $\lambda$ or assuming $\lambda=4$ (which is closer to the estimates found by Nelson and Plosser (1982)) are similar to those obtained using HP1600. Absolute standard errors, however, differ. Therefore, although the ordering of relative variabilities across series is unaltered by arbitrary choices for

\footnotetext{
${ }^{10}$ Under standard regularity conditions outlined e.g. in Newey-West (1987), the statistics $J_{1}=\left(\operatorname{var}_{x}(i)-\right.$ $\left.\operatorname{var}_{x}(H P 1600)\right) V_{1}^{-1}\left(\operatorname{var}_{x}(i)-\operatorname{var}_{x}(H P 1600)\right)$ and $J_{2}=\left(\operatorname{cov}_{x, G N P}(i)-\operatorname{cov}_{x, G N P}(H P 1600)\right) V_{2}^{-1}\left(\operatorname{cov}_{x, G N P}(i)-\right.$ $\left.\operatorname{cov}_{x, G N P}(H P 1600)\right)$ are distributed $\chi^{2}(1)$ where $i$ stands for detrending method, $x$ for the particular series examined and $V_{1}$ and $V_{2}$ are the asymptotic covariance matrices of the random variables $\left[\operatorname{var}_{x}(i), \operatorname{var}_{x}(H P 1600)\right]$ and $\left[\operatorname{cov}_{x, G N P}(i), \operatorname{cov}_{x, G N P}(H P 1600)\right]$ respectively.

${ }^{11}$ The tests for excess skewness and excess kurtosis used here are those presented in Kendall and Stuart (1958).
} 
$\lambda$, estimates of the absolute variability of the series may be subject to specification errors. The relative variabilities of series detrended with RW are also close to those obtained with the HP1600, confirming some of the properties of the two filters described by King and Rebelo (1989). The two filters, however, extract different amounts of absolute variability for each series. Finally, the relative variabilities obtained with UC, HAMIL and MFD filters differs substantially from those obtained with HP filters, with consumption, hours and wage being the most affected.

There is also a wide range of results in the cross correlations of the cyclical components of the various series with GNP. For example, the contemporaneous cross correlation of consumption with GNP varies, across detrending methods, from 0.38 to 0.94 and that of hours and output varies from 0.17 to 0.88 . Even more striking is the range of cross correlations between GNP and productivity which goes from -0.41 to about 0.75 . Therefore, the qualitative conclusion that productivity (and the real wage) is procyclical (see e.g. Mankiw (1989), Prescott (1990)) depends on the detrending method employed. Similarly, the quantitative result that the contemporaneous correlation between productivity and output is small (see e.g. McCallum (1988)) or that the contemporaneous correlation between employment and output is large (see e.g. Stock and Watson (1990)) is not robust and depends on the detrending methods employed. In general, the largest range in lead and lag correlations occurs when hours and GNP are considered, the smallest range occurs for the cross correlations of consumption and output.

Among detrending methods, the HP1600 filter produces the highest contemporaneous correlation between output and hours and output and investment. Also, the contemporaneous cross correlation obtained with HP1600 filtered data are significantly larger than those obtained with an optimal $\lambda$ or with $\lambda=4$. Except for FD1 detrended data, the hypothesis that the cross correlations reported in the table are the same as those obtained with a HP1600 is rejected.

The ranges of correlations between wage and past output and wage and hours provide the basis for two observations. Summers (1986), McCallum (1988), Mankiw (1989)) and others have suggested that the presence of a negative correlation between current productivity and past output is an indicator of the existence of labor hoarding on the part of firms. Here I find that the wage series is very negatively correlated with output when LT, POLY, MLT, MFREQ and COIN are used, but with all the other methods the correlation is positive. Therefore, tests of the labor hoarding hypothesis computed using one period lagged correlations produce results which are method dependent. 
Kydland and Prescott (1988) report that the contemporaneous correlation between a standard measure of hours and the real wage is very low when HP1600 detrended data are used. They suggest that measurement errors may be an important determinant of this correlation and attempt to reconstruct a wage series which is free from these errors. Here I find that the contemporaneous correlation between hours and the real wage can go from slightly negative to approximately 0.6 . In addition I find that there is no clear agreement among methods which use orthogonal decompositions nor among methods which assume that secular and cyclical components are correlated. For example, the BN and UC procedures, which both assume that the components are correlated, give exactly opposite results. Therefore, while measurement errors may well be an important issue, their impact on these correlations depends on the detrending method employed.

\subsubsection{Higher moments}

Current work cataloging properties of business cycles typically report only second moments (see e.g. Kydland and Prescott (1990) or Stock and Watson (1990) for the US, Englund, Persson and Svensson (1991) for Sweden, Danthine and Girardin (1989) for Switzerland, Brandner and Neusser (1990) for Germany and Austria). Lingering in the back is the implicit assumption that the series are zero mean normal stochastic processes so that second moments summarize all information contained in the data. Recent work by Neftcy (1984), Falk (1986), Delong and Summers (1986), Pfann (1991) have examined higher than second moments of the data to detect asymmetries or fat tails in the distribution of the cyclical components of some real variable. In the present context an examination of the properties of higher moments is useful both to indicate whether any detrending procedure distorts properties of the data and to informally test of the appropriateness of the normality assumption.

The results support previous conclusions by Falk (1986) and Delong and Summers (1986). No major differences across detrending methods emerge from the tables. For most detrending methods, there is a tendency for all series to display negative skewness and a slight positive excess kurtosis. However, for all procedures except SEGM and HAMIL, the normality assumption for the cyclical components of the six series is appropriate. With SEGM filtering wage is highly negative and capital highly positively skewed, indicating a possible misspecification in the breaking point of the trend for these variables. With HAMIL filtering the capital series is 
negatively skewed. In all three cases the cyclical components are highly leptokurtic.

It is interesting to compare the coefficient of skewness and kurtosis obtained from the data before and after detrending ${ }^{12}$. For the original data all series are slightly left skewed but the coefficient of skewness is not different from zero. Wage and capital, on the other hand, have a marginally significant leptokurtosis. Therefore, most detrending procedures avoid the introduction of severe distortions in these moments and do not seem to affect the higher order properties of the data differently.

Two conclusions can be drawn from the results presented so far. First, qualitatively and quantitatively the second order properties of the data strongly depend on the detrending procedure used. Second, higher moments of the cyclical data are substantially insensitive to the detrending method employed. To examine the effects of various detrending procedures on autocorrelation properties and the long run cross correlations I next turn to examine the gain function of the filters and the impulse response function of the system.

\subsection{Gain functions}

To examine the distortions introduced by the various procedures at different frequencies it is useful to examine a plot of the estimated gain function of the detrending filters. Let $S_{y}(\omega)$ be the spectrum of the original series and $S_{c}(\omega)$ the spectrum of the detrended series. $S_{y}(\omega)$ and $S_{c}(\omega)$ are linked by $S_{c}(\omega)=\Gamma(\omega) S_{y}(\omega)$ where $\Gamma$ is the transfer function of the filter which can be obtained (see Priestley, 1981, p.265) as:

$$
\Gamma(\omega)=\int_{-\infty}^{\infty} a(u) e^{i \omega u} d u
$$

where $a(u)$ is the (double-infinite) polynomial representation of the detrending filter. Thus, the transfer function is the Fourier transform of the detrending filter and its plot by frequency is useful to assess the effect of detrending at frequencies away from zero. Ideally, an appropriate detrending filter is one which has zero power at low frequencies and introduces no additional power at other frequencies. In practice, the adaptation of the ideal filter to a finite weight context and the estimation of its parameters makes the filter imperfect, induces leakages to low frequency components and distorts its ideal shape (see e.g. Koopmans (1974)).

A useful characterization of the transfer function is in terms of the gain function $\gamma(\omega)$ and

\footnotetext{
${ }^{12}$ Since the test for skewness and kurtosis are invalid in the presence of serial correlation, both the original and the filtered series are prewhitened with 12 lags before the test statistics are computed
} 
the phase shift $\phi(\omega)$ which can be obtained by writing $\Gamma(\omega)$ in polar form as:

$$
\Gamma(\omega)=\gamma(\omega) e^{i \phi \omega}
$$

The gain function measures the increase in the amplitude of the cycles of the filtered series over the original one, while the phase measures how much cycles are shifted by the filtering procedure 13 .

Plots of the estimated gain functions are contained in the appendix. Some filters, including HP1600, BN, UC, LT, POIY and SEGM, seem to amplify the importance of cycles at $\pi / 8$ (16 quarters) relative to others. This feature is stronger with HP1600 and FD2 and the gain function for these two filters is close to 1 at these frequencies. This observation suggest that some of the features reported in tables 1 and 2 could be an artifact of the detrending procedure employed. In particular, the relative high cross correlations obtained with these filters may reflect properties of the filters more than properties of the data. Cogley (1990) discovered this feature for the HP1600 filter when the true data generating process is a set of random walks. Here we see that the result is more general: several detrending methods may induce time series properties in the data which mainly reflect properties of the filters. Also, it is worth noting that when $\lambda$ is optimally estimated the gain function does not amplify cycles of 16 quarters and that the gain function of the HP4 and RW filters smoothly eliminate power at business cycle frequencies.

A few anomalies emerge when UC and HAMIL procedures are used. First, the filters extract different variability around business cycle frequencies for different series. Second, while there appears to be little distortion relative to other methods at business cycles frequencies for output and consumption, there is substantial distortions in the wage and hours series at these frequencies.

Finally, all filters leave the largest amount of high frequency variation in investment. The high frequencies behavior of other series is method dependent.

\subsection{Impulse Responses}

One additional linear summary statistic I examine is the impulse response function when GNP is shocked by one standard deviation in a system with all six variables included and triangularized in the order GNP, Consumption,Investment, Hours, Capital and Wage. Impulse response plots

\footnotetext{
${ }^{13}$ Since all the filters considered are one sided-nonsymmetric, the phase shift is different from zero at least at some frequencies. For reasons of space I do not discuss them here.
} 
are reported in the appendix. Several features of the impulse responses need be noted. First, the average length of an output cycle in response to a shock in output varies with detrending procedure. For example, the average cycle is about 3.5 years with the HP1600 filter, a little less than 2 years with the HP4 filter and about 1 year with the RW filter. Second, the response of investment has different persistence depending on the detrending method employed. Third, the sizes of the peaks response in consumption and investment depend strongly on the detrending method. For example, the peak response in consumption varies from 0.6 to 5.5 of the shock in GNP. Finally, the timing of the peak responses of the six variables falls into two major categories. In the first category, which includes most univariate filters (all HP filters, RW, BN, Linear and Polynomial detrending methods and FD1), a shock to output produces a peak response in output and hours instantaneously, a peak response in consumption and investment with a 3 quarter lag, a peak in capital with a 3-6 quarter lag and a peak in wage at lags between 1 and 4 quarters. The timing of the peak response in the wage series seems to be the major qualitative difference among these methods. In addition, in all cases the size of the instantaneous increase in productivity (GNP/Hours) is always larger than the size of the peak response in real wage ${ }^{14}$. In the second category which includes COIN (and somewhat MFD) there is an instantaneous and very large peak response in consumption which is accompanied by a negative response in investment, hours and capital and very slow convergence to the steady state ${ }^{15}$ The peak responses in investment, hours and wage occur approximately five quarters after the shock in GNP.

The two patterns of responses seems to agree with two different theoretical characterizations of business cycle fluctuations. The first fits a RBC tale: a temporary shock to output increases labor demand, hours go up and the real wage goes up'swithin a year's time. As the real wage increases, consumption increases and investment follows. Since productivity increases more than the real wage, profits increase and payments to holders of capital rise as well (average real return to capital $=\mathrm{GNP} /$ capital is above zero in the first stages of the cycle). Therefore the real return per unit of capital invested increases. This increase is contemporaneously correlated with the increase in hours. Therefore hours move together with this measure of the real rate, a result which is consistent the $\mathrm{RBC}$ emphasis on intertemporal substitution of labor. In addition, the

\footnotetext{
${ }^{14}$ With the UC filter the instantaneous increase in productivity is approximately of the same size as the increase in real wage. Note that in this case the peak response of consumption lags the peak response of investment by about 3-4 quarters.

${ }^{15}$ The negative contemporaneous response of investment to shock in output have been found also by Warne and Vredin (1991) using a COIN filter on Swedish data.
} 
responses of productivity are approximately coincident with the responses of GNP and hours, a result which goes against the labor-hoarding explanation of business cycle fluctuations (see e.g Kydland and Prescott (1982), Mankiw (1989)).

The second pattern of responses, on the other hand, fits the NeoKeynesian perspective better. The impulse responses obtained when series are detrended with COIN seem to indicate that agents confuse permanent and temporary technological shocks. A one standard error shock in GNP increases consumption by about 5 times that amount. To achieve this consumption increase, the economy depletes the capital stock and invest negative amounts. At least in the first phase of the cycle, productivity is negatively related to (and lags) shocks in output, a pattern which fits the labor-hoarding story (see Summers (1986) or McCullum (1989)). In addition, since agents interpret a change in GNP and consumption as permanent, they increase leisure (wealth effect). This demand driven expansion causes output to further increase in the short run, possibly through the use of idle capacity, driving hours and real wages up. When agent realize that the output shock was temporary, previous decisions are reverted: hours stay above their long run average for a long period, consumption precipitously decreases and the destruction of the capital stock is reversed. Reconstruction is completed in about 48 quarters when the capital stock has achieved its steady state path.

To conclude, impulse responses differ both quantitatively and qualitatively depending on the detrending methods employed. While quantitative differences are not surprising since different filters extract different amounts of information in the six variables, the qualitative results are more disturbing. Depending on the detrending method employed contrasting theories of business cycles fluctuations are consistent with the data.

\subsection{Some nonlinear statistics}

This subsection presents two summary statistics characterizing the nonlinear properties of the cyclical components of the data. I report how each detrending procedure fares in reproducing (i) the timing of recessions and expansions as dated by NBER researchers and (ii) the distributional features of the duration of NBER expansions, recessions and complete cycles. These statistics are presented in an attempt to discover whether any detrending method can provide statistical (and/ or economic) foundation to the procedure used by the NBER researchers. Also, since the second statistic examines of the entire distributional features of the data it provides a more stringent criteria to judge the relative performance of various detrending methods. 


\subsubsection{Dating Turning Points}

I follow the NBER procedure and define a turning point as the first of (at least) two consecutive sign changes in the cyclical component of GNP. Using this definition, table 5 reports the dating of turning points for each detrending method. For the sake of comparison NBER dates and the dates obtained using the Department of Commerce Composite Leading Index (CLI) are also reported. For a graphical comparison, NBER recessions are depicted as shaded areas on the cyclical component of output for each detrending method (see figure 2).

From table 5 it is clear that HP, BN and FD1 are the only methods which capture all NBER turning points (plus some additional false alarms) although in some cases the lag in recognizing a turning point can be as large as four quarters. For all the other methods, either the dating is lagging by more than four quarters or some turning points are not identified. The results obtained with UC, LT and all multivariate detrending methods are very surprising because 3-4 NBER turning points are completely missed and, as a consequence, extremely long cycles are produced in the data. For example, using the cointegration detrending filter, the US economy is classified to be in a recession from 74,1 until the end of the sample, while using a linear detrending method, the $80,2-86,3$ period is classified as a recession. The most frequently missed turning points are those initiating mild and short contractions or expansions (see e.g. 69,4 and $70,4)$. Note also that the Hamilton filter incorrectly identifies 9 of the 11 NBER turning points of the sample. Therefore if one uses a two consecutive sign change rule (as opposed to Hamilton's (1989) rule of being in one state with at least 0.5 probability), the method is not successful in dating turning points.

\subsubsection{Duration Dependence}

Using different techniques Neftcy (1984), Stock (1987) and Diebold and Rudebush (1990) examined various forms of time deformations, in an attempt to assess either whether business cycles evolve according to non-calendar time or whether they have recurrent (geometrical and statistical) patterns.

Here I perform calculations similar to those that Diebold and Rudebush (1990) performed using NBER dated cycles and examine the duration dependence of contractions, expansions, peak to peak cycles and trough to trough cycles for each detrending method. Examining the duration dependence of each of these four states (i) may indicate the presence of nonlinearities 
and asymmetries in the phases of business cycles and (ii) provides information about the likelihood of each phase to terminate the longer the time span elapsed from its start. The tests are performed using Stephen's (1978) variant (which accounts for minimum duration) of the Shapiro and Wilk's (1972) exact small sample test. The minimum duration is assumed to be two quarters for each phase and four quarters for each complete cycle.

Table 6 reports the value of the statistics for contractions, expansions, peak to peak cycles and trough to trough cycles and the number of durations available for each phase for each of the detrending methods. A "*" indicates that the hypothesis of no duration dependence is rejected. It is comforting to see that most detrending procedures induce no duration dependence in all four business cycle phases (Diebold and Rudebush found no evidence of duration dependence in NBER dated post-WWII cycles). Among univariate procedures only the UC filter induces duration dependence in GNP contractions and expansions but not in full cycles. All multivariate filters, on the other hand, induce duration dependence in contractions, MFD also in expansions and peak to peak cycles and COIN in expansions. One should note, however, that since in all these cases the number of durations is very small, caution should be used in interpreting the results. Table 6 also indicates that no asymmetries are present in business cycle phases, confirming Stock (1987) but in contrast to results obtained by Neftcy (1984) and Pfann (1991) who find asymmetries in unemployment. Only with MLT do contractions and expansions have different duration dependence structures and only with MFD do peak to peak and trough to trough cycles have different duration structures ${ }^{16}$.

\section{Seasonally Unadjusted Data}

\subsection{The Data}

The data set here is constructed from Barsky and Miron's (1989) data and maintains as much comparability as possible with the seasonally adjusted data used in the previous section.

GNP measures total output produced in 1982 dollars, consumption measures consumption of nondurables plus services by domestic residents in 1982 dollars, and investment measures fixed investment in plants and equipment plus consumer durables. Hours measures the average

\footnotetext{
${ }^{16}$ To check the robustness of these results I also perform the tests recursively. That is, given that we observed n-1 durations of a particular phase, we would like to know whether the probability of the n-th duration of that phase depends on the length of time since its beginning. The results of these tests, which are presented in the appendix, confirm the conclusions obtained using the full sample of durations.
} 
weekly hours of production workers in private, non agricultural activities. Quarterly data is constructed as an average of monthly numbers. The wage series measures the average deflated (by CPI) hourly earnings of private, nonagricultural productive workers. Again, quarterly data is computed as an average of monthly numbers. The capital stock series is constructed using the value of the capital stock in 1948, adding the investment series and using a $2.5 \%$ depreciation rate per quarter. Data for the first four variables is available from 1946,1 to 1985,4 , while data for hours and the real wage starts at 1964,1 . Time plots for the log of the data, their estimated $\log$ spectrum and the estimated coherence of each series with GNP appear in figure 3. Figure 4 plots the cyclical components of GNP produced with various detrending procedures. Shaded areas in each box represent recessions according to the NBER chronology ${ }^{17}$.

\subsection{The Plots}

Plots of the log of the data are comparable to those presented in figure 1. All series except hours exhibit upward movements after the removal of an exponential trend and all but wage and capital display some seasonal fluctuations. The seasonal pattern of GNP, consumption and investment is evident from the log spectra of the series which display peaks at both seasonal frequencies. The seasonal pattern of hours is statistically small but appears to be economically significant. The correlation between the five series and GNP at seasonal frequencies is in general small, except for the correlation of consumption with GNP. Hours and GNP have a small coherence at all the frequencies of the spectrum, a result which partially conflicts with the evidence presented with seasonally adjusted data and may be the result of different measurement errors present in the two hours series.

The plots of detrended GNP are somewhat difficult to interpret because of the overwhelming dominance of seasonal variability. When the three HP, the RW and the BN filters are used, the seasonal variability swamps all other fluctuations in the GNP series. The results with the UC filter are easier to interpret because seasonal fluctuations appear in the error term of equation (10). This filter produces peaks and troughs in GNP which are approximately coincident with NBER dates but induces a nonzero mean in the detrended GNP. As with seasonally adjusted data, the plots of HP1600 and FD1 detrended GNP are very similar although the FD1-detrended GNP is much more variable. Finally, the time paths of the cyclical component of GNP obtained

\footnotetext{
${ }^{17}$ This section does not report results obtained with the Hamilton or the COIN filters because, in the first case, the algorithm did not converge in all six cases and, in the second case, no common stochastic trend seems to exist.
} 
with the two multivariate filters significantly differ from most time paths obtained with univariate filters (the exception is LT). Also, the presence of long swings in detrended GNP indicates that the two multivariate filters fail to remove a substantial amount of lung run variability in the series.

\subsection{Summary Statistics}

Tables 7 through 10 report the absolute standard error of the cyclical component of GNP, the relative standard error of the other five series (as a percentage of GNP), the short term cross correlations with GNP and the skewness and kurtosis coefficients obtained with various detrending methods. In tables 7 and $8 \mathrm{a}$ " $*$ indicates that the statistic in the cell significantly differs (at $5 \%$ confidence) from the corresponding statistic obtained with the HP1600 filter. In tables 9 and $10 \mathrm{a}$ "*” indicates that the statistic in the cell significantly differs from the statistic which would appear if the series had a normal distribution.

As in the case of seasonally adjusted data, the standard errors of the detrended GNP vary greatly across detrending methods. The variability of GNP is maximal when MFD is used (13.12) and minimal when UC is used (0.69). The range of variation across detrending methods of the relative variabilities of the five series to GNP is very large as well. For example, all series except investments can be either more or less volatile than GNP. Particularly striking are the results obtained for the hours series: depending on the method used, the variability of hours can be between $5 \%$ and $1175 \%$ of the variability of GNP.

The HP1600 filter leaves a larger amount of cyclical variability in GNP than in other series (relative to other methods). This causes the relative variability of the five series to be in the lower quartile of the distribution across methods. The exception is the investment series which seems to have most of its mass in the region where the HP1600 filter has its peak (around 16-24 quarters).

The range of the contemporaneous cross correlations of consumption and investment with GNP is relatively small. For both series and for most detrending methods these correlations are in the neighborhood of .85 . However, the contemporaneous correlations of hours, real wage and capital with GNP and the lead and lag correlations of all series with GNP range from significantly negative to near unity. Among detrending methods, HP, RW and BN filters induce negative cross correlations at one lead or lag while LT, SEGM and POLY filters induce very strong and significantly positive cross correlations at one lead or lag. Particularly relevant here 
is the large disparity across detrending methods in the correlations of wage (and productivity) with past output. Once again, the results are consistent with both a labor hoarding phenomena (negative correlation) and with its absence (positive correlation).

Except for detrended consumption, hours and capital with the SEGM filter and hours with FD1 filter, no series display any significant skewness. Since in the original data consumption displays a positive and significant skewness coefficient, the asymmetric behavior of consumption appears to be due to very long cycles, which are wiped out by the detrending procedures. One explanation for the appearance of skewness in hours and capital detrended with the SEGM filter is that there is an incorrect (or unnecessary) segmentation of the trend of these series.

For most detren ding methods (except BN, POLY,FD2 and MFD), the cyclical components of consumption and hours display strong leptokurtic behavior even after deterministic seasonality is taken into account. Since this behavior appears in the raw data as well, the clustering of observations in the tails of the distribution comes from cycles with a short period of oscillation. Note also that only 2 of the 13 methods produce leptokurtic behavior in GNP and none in investment. Since fat tail behavior appears for both series in the raw data, the clustering of observations in the tails of the distribution comes from cycles with periodicity in excess of 20-24 quarters ${ }^{18}$.

\section{The Seasonal and the Business Cycle}

Barsky and Miron (1989) examined the behavior of US macroeconomic variables at business cycle and seasonal frequencies to determine whether stylized facts of the US business cycle persist at seasonal frequencies.

Acknowledging that features of business cycles may be dependent on the detrending method, they presented two sets of results (one obtained detrending the data with HP1600 and one detrending the data with the RW filter) and found some differences in the resulting statistics. It is of interest to repeat their exercise with a wide variety of detrending filters for two reasons. First, to see whether Barsky and Miron 's conclusions hold under a variety of detrending procedures.

\footnotetext{
${ }^{18} \mathrm{As}$ in the case of seasonally adjusted data, I attempted to date turning points for GNP with each detrending method. The results are not reported here because most methods fail to reproduce 4 or more NBER turning points. For example, when using HP1600 detrended GNP and the two-quarters-sign-change rule, only 2 NBER turning points were recognized within 6 quarters (plus or minus 3) of the NBER date. This failure was particularly evident in those cases where seasonal variability accounts for most of the fluctuations in the cyclical component of GNP.
} 
Second, to check whether the lack of robustness I found is confined to cyclical fluctuations or whether it applies to seasonal fluctuations as well.

Comparing the behavior at seasonal and business cycle frequencies of the spectrum, as Barsky and Miron did, is successful only if a sufficiently large number of observations at business cycle frequencies is available. Since the data set employed here is too short, I examine the seasonal and business cycle with an alternative strategy. Instead of comparing the second order properties of seasonally non-adjusted data at seasonal and business cycle frequencies, I compare statistics obtained with seasonally adjusted and seasonally non-adjusted data. Because the two data sets measure the same aggregates and differ, roughly speaking, only at seasonal frequencies, we can describe the features of the seasonal cycle and quantify its contribution to the second order properties of the data by examining (i) the incremental variability existing in each series (compare tables 1 and 7), (ii) the differential level of cross correlations (compare tables 2 and 8), (iii) the differences in the estimated gain functions and (iv) the differences in the impulse responses for the two data sets.

\subsection{Standard Errors and Correlations}

On average the variability of the seasonal component of GNP is as big as the variability of its cyclical component (i.e. the standard error of output in table 7 is about twice the standard error of output in table 1 for all detrending methods). Two exceptions are noticeable. When BN is used the variability of the seasonal component of GNP is smaller than the variability of its cyclical component. When HP4 is used the opposite is true. Because the gain function of the HP4 filter has its peak at cycles with about one year periodicity, the variability of detrended seasonally non-adjusted GNP turns out to be more than four times the variability of detrended seasonally adjusted GNP. A similar but smaller effect also emerges for HPOPT detrended GNP.

The ordering of the absolute variability of GNP across methods is largely preserved when seasonally non-adjusted data is used, apart from the inversion of POLY and SEGM filtered data. Also, as in the case of seasonally adjusted data, HP1600 and FD1 produce approximately the same results. The ordering of relative variability of the five variables across methods is also preserved when seasonally non-adjusted data are used. The most significant difference between the two data sets occur with HP4 detrended series because the seasonal variability of GNP and consumption is enhanced. Therefore, except in a few cases, the presence of seasonal fluctuations does not substantially alter the properties of detrending filters. 
Some clean quantitative statements can be made for the consumption and investment series. In general, consumption is at least two or three times as volatile as output at seasonal frequencies. The presence of a strong excess seasonal variability in consumption relative to output is picked up by almost all methods. At nonseasonal frequencies the volatility of consumption is between 0.53 and 1.53 of the volatility of output, with most of the methods suggesting a relative volatility less than one. Investment is slightly less volatile than output at seasonal frequencies and the relative volatility of the two series is roughly maintained across the business cycles frequencies of the spectrum.

Results for the other series are much less clean. Hours and wage are much less volatile than output at seasonal frequencies (although for hours BN, SEGM and FD2 methods give the opposite conclusions). At other frequencies the variability of these two series is approximately of the same order of magnitude as the variability of GNP. Finally, the relative variability of the capital stock is between $1 / 6$ and $2 / 3$ of output at seasonal frequencies (compared with $1 / 20$ to 4 times at nonseasonal frequencies). It is worth noting the complete lack of seasonal variability in the capital stock at the frequency corresponding to a one year cycle.

Although the short term cross correlations are not very informative about features of the seasonal and the business cycle, a comparison of tables 2 and 8 does highlight some interesting aspects of the data. First, the first order serial correlation coefficient of GNP is negative and close to -0.5 for HP, RW, BN filters. Since all these filters first difference the data and then apply some smoothing filter (see Cogley (1990)), this result indicates some degree of overdifferencing. Second, for all detrending methods, the contemporaneous correlations of consumption with GNP are higher when seasonally nonadjusted data are used, while the contemporaneous correlations of investment and hours with GNP are somewhat lower. This confirms that the coherence of consumption with GNP at seasonal frequencies is higher than at other frequencies and the opposite is true for the coherence of investment and hours with GNP. Third, lag and lead cross correlations are uniformly lower with seasonally non-adjusted data. Finally, the cross correlations of wage and capital with GNP display significant sign difference both across detrending methods and across data sets.

\subsection{Impulse Responses and Gain Functions}

One final piece of evidence in the comparison between the seasonal and the business cycle properties of the data under different detrending filters comes from the impulse responses and 
from the estimated gain functions ${ }^{19}$. Eyeballing the impulse responses, it is immediate to see that there is no coherent pattern of results among detrending methods across the two data sets. Most detrending methods alter the qualitative features of the responses of the two data sets (the only exception here is SEGM). For example, with RW detrending, consumption and hours are much more persistent when seasonally non-adjusted data are used. The most evident difference between the two data sets is in the responses of consumption which, with seasonally non-adjusted data, can display long swings (see HPOPT), sharp peak responses (see BN) or a long delay in the peak response (see FD1). Once again, HP1600 and FD1 produce similar responses for all variables except consumption.

Quantitatively, the largest differences emerge in the responses of hours and wage. With seasonally adjusted data the peak response in wage is twice as big as the peak response in GNP and the response of hours is negligible. On the other hand, with seasonally non-adjusted data the peak response in wage is small and the peak response in hours is twice as big a the peak response in GNP.

Finally, the estimated gain functions of the filters are not substantially altered across the two data sets. However with seasonally non-adjusted data, the filters leave uniformly more variability in the cyclical components of the series at every frequency of the spectrum.

Three conclusions can be drawn from the above discussion. First, while different detrending methods induce substantial disparities in the properties of the data at business cycle frequencies, their effect at seasonal frequencies is qualitatively similar. Second, because of these similarities, a few quantitative facts concerning the behavior of consumption and investment relative to GNP at seasonal frequencies can be stressed. Consumption is $2-3$ times more volatile than output at seasonal frequencies and its correlation with output at these frequencies is much higher than at nonseasonal frequencies. The relative volatility of investment to output is roughly the same at all frequencies, with investment displaying a smaller seasonal pattern than GNP. Third, because the behavior of consumption, hours, wage and capital relative to output differs substantially at seasonal and nonseasonal frequencies, I conclude that the seasonal and the business cycle in the US are not alike.

\footnotetext{
${ }^{19}$ Plots of the gain functions and of the impulse responses for seasonally non-adjusted data appear in the appendix.
} 


\section{Conclusions}

This paper examines how different detrending methods affect a set of summary statistics of the cyclical components of some US real variables.

I compare the properties of the cyclical components of six variables (GNP, Consumption, Investment, Hours and Productivity) obtained using nine univariate (Hodrick-Prescott (HP), Beveridge-Nelson (BN), Linear (LT), Polynomial (POLY), Segmented (SEGM), First Order Differencing (RW), Unobservable Components (UC), Frequency Domain Masking (FD), Hamilton's 2-state Markov chain (Hamilton)) and three multivariate (cointegration, common deterministic trend and common trend) detrending techniques for both seasonally adjusted and seasonally unadjusted data. For each of these methods I report a set of linear summary statistics (moments of the data, the short term cross correlations with GNP, the impulse response function when output is shocked and the estimated transfer function of the detrending filter for each series) and two nonlinear statistics (dating of business cycles, duration dependences of half and full cycles).

The paper documents a wide range of outcomes with little agreement in the qualitative and the quantitative properties of the standard errors and of the cross correlations. It is shown that the qualitative response of consumption, investment, etc. to a typical shock in GNP can result in two broad patterns: one consistent with RBC stories and one consistent with NeoKeynesian tales. Quantitatively speaking, the length of a typical cycle and the peak response of the variables strongly depend on the detrending procedure employed. It also shown that most detrending methods induce distortions across variables at business cycle frequencies which are of nonnegligible size. Finally, the paper shows that the properties of seasonal and business fluctuations are substantially different regardless of the detrending procedure employed. I find that there are certain features of business cycles that are invariant to detrending methods (higher moments, duration dependence) but these are not the features considered by modern business cycle researchers.

A few conclusions can be drawn from the exercise. First, the practice of solely employing HP1600 filter in compiling business cycle statistics is dangerous. The HP1600 filter produces results which are similar those obtained with conventional high-pass filters (e.g. frequency domain masking the low frequency components of the data). However, it also induces extreme second order properties in the detrended data and may misdirect theoretical research trying to 
cope with them (see e.g. Hansen's (1985) effort to remedy Kydland and Prescott's (1982) failure to replicate the variability of hours or Christiano's (1988) attempts replicate with the size of the volatility of investment) ${ }^{20}$.

Second, since there are no quantitative stylized facts and very few qualitative features of the data which are robust across detrending methods, the practice of building theoretical models with an eye to quantitatively match business cycle facts warrants a reconsideration. Because the major differences occur exactly around business cycle frequencies, the exercises should at least be enlarged to provide results obtained with different detrending methods. Third, multivariate detrending methods which have their base in economic theory seem to produce very different results than statistically based univariate procedures. However, since at least for the two data sets used here, there is very weak evidence of common (deterministic or stochastic) trends, caution should be exercised in imposing theoretical restrictions which are far from being satisfied in the data. Finally, since the seasonal and the business cycles are hardly similar, the recent attempts by Braun and Evans (1990) and Chattarjee and Ravikumar (1990) to provide a unified explanation of economic fluctuations are misdirected. Most of the action in the consumption series is at seasonal frequencies while most of the action in investment and hours appears at business cycle frequencies. Explaining the asymmetric behavior of these series at business and seasonal frequencies should be an important area of future research.

\footnotetext{
${ }^{20}$ One could add to this list the excess smoothness of consumption relative to output (see Deaton (1987)). Consumption is smoother than GNP only when seasonally adjusted data are used. Across detrending methods, which impose a drifting trend there is not so much evidence for the excess smoothness hypothesis except perhaps when UC detrending is used
} 


\section{References}

[1] Anderson, T. (1971), Statistical Analysis of Time Series, New York, N.Y., Wiley and Sons.

[2] Barsky, R and Miron J. (1989), "The Seasonal Cycle and the Business Cycle", Journal of Political Economy, 97, 503-534.

[3] Baxter, M. and A. Stockman (1989), "Business Cycles and Exchange Rate Regime: Some International Evidence", Journal of Monetary Economics, 23: 377-400.

[4] Baxter, M. (1991), "Business Cycles, Stylized Facts, and the Exchange Rate Regime: Evidence from the United States", forthcoming, Journal of International Money and Finance

[5] Beveridge S. and C. Nelson (1981), "A New Approach to Decomposition of Economic Time Series into Permanent and Transitory Components with Particular Attention to Measurement of the 'Business Cycle'," Journal of Monetary Economics, 7: 151-174.

[6] Braun, T. and Evans, C. (1990), "Seasonality and Equilibrium Business Cycle Theories", Institute for Empirical Macroeconomics, Federal Reserve Bank of Minneapolis, Discussion Paper 43.

[7] Brandner, P. and Neusser, K. (1990), "Business Cycles in Open Economies: Stylized Facts for Austria and Germany", Ostrreichisches Institut fur Wirtschaftsforschung, working paper 40.

[8] Burns, A. and Mitchell W. (1946) Measuring Business Cycles, New York: N.Y., NBER.

[9] Canova, F. (1991), "Forecasting a Multitude of Time Series with Common Seasonal Patterns", forthcoming, Journal of Econometrics.

[10] Carvalho, J., Grether, D. and Nerlove, M. (1979), Analysis of Economic Time Series: A Synthesis, New York, N.Y., Academic Press.

[11] Chattarjee, R. and Ravikumar, B. (1990) "A Neoclassical Model of Seasonal Fluctuations" University of Iowa, manuscript.

[12] Christiano, L. (1988), "Why does Inventory Investment Fluctuate So Much", Journal of Monetary Economics, 21(2/3): 247-280. 
[13] Christiano, L. (1989) "In Search for a Break in GNP", Federal Reserve Bank of Minneapolis, Research Department, manuscript.

[14] Christiano, L. and Eichenbaum, M. (1990) "Unit Roots in GNP: Do We Know and Do We Care ", it Carnegie Rochester Conference Series in Public Policy, 32: 7-62.

[15] Coddington, J. and Winters, A. (1987), “The Beveridge-Nelson Decomposition of a Time Series: A Quick Computational Approach" Journal of Monetary Economics, 19:125-127.

[16] Cogley, T. (1990), "Spurious Business Cycle Phenomena in HP detrended Series", University of Washington, manuscript.

[17] Danthine, J.P. and Girardin, M. (1989) "Business Cycles in Switzerland. A Comparative Study", European Economic Review, 33: 31-50.

[18] Deaton, A. (1987), "Life Cycle Models of Consumption: Is the Evidence Consistent with the Theory", in Advances in Econometrics:Fifth World Congress, vol 2, edited by T. Bewley, New York, Cambridge University Press.

[19] Diebold, F and Rudebush, G (1990), "The Duration Dependence of the American Business Cycle", Journal of Political Economy, 98: 596-616.

[20] DeLong, B. and L. Summers (1986), "Are Business Cycles Asymmetric?", in R. Gordon (ed.) The American Business Cycle: Continuity and Change, Chicago, University of Chicago Press, p. 166-178.

[21] Englund, P., Persson, T. and Svensson, L. (1991), "Swedish Business Cycles: 1861-1988", Rochester Center for Economic Research, Working Paper 275.

[22] Falk, B. (1986), "Further Evidence on the Asymmetric Behavior of Economic Time Series over the Business Cycle", Journal of Political Economy, 94(5) 1096-1109.

[23] Ghysels, E. (1990), “ The Business Cycle, The Seasonal Cycle or Just any Cycle ?", University of Montreal, manuscript.

[24] Hansen, G. (1985), "Indivisible Labor and the Business Cycle," Journal of Monetary Economics 16: 824-840. 
[25] Hamilton, J. (1989), "A New Approach to the Economic Analysis of NonStationary Time Series and the Business Cycle", Econometrica 57: 357-384.

[26] Harvey, A. C.,(1981) Time Series Models, New York, N.Y.: Wiley and Sons.

[27] Harvey, A.C. (1985), "Trends and Cycles in Macroeconomic Time Series",Journal of Business and Economic Statistics, 3(3): 216-227.

[28] Hodrick, R. and E. Prescott, (1980) "Post-War U.S. Business Cycles: An Empirical Investigation," Carnegie Mellon University, manuscript.

[29] Kendall and Stuart (1958), Advanced Statistics, New York, N.Y: Hafner.

[30] Kimeldorf G. and G. Wabha (1970), “ A Correspondence Between Bayesian Estimation of Stochastic processes and Smoothing by Splines", Annals of Mathematical Statistics, 41: 495-502.

[31] King, R. and C. Plosser (1989), "Real Business Cycles and the Test of the Adelmans", Rochester Center for Economic Research, Working paper 204.

[32] King, R., C.Plosser and Rebelo S. (1988) "Production, Growth and Business Cycles: I. The Basic Neoclassical Model", Journal of Monetary Economics, 31(2/3): 195-232.

[33] King R., C. Plosser, J. Stock, M. Watson (1991), "Stochastic Trend and Economic Fluctuations," forthcoming, American Economic Review.

[34] King, R. and S. Rebelo (1989), "Low Filtering and the Business Cycles", University of Rochester, working paper 205.

[35] Koopmans, L.H. (1974), The Spectral Analysis of Time Series, New York, N.Y:Academic Press.

[36] Kydland, F. and C. Prescott (1982), "Time To Build and Aggregate Fluctuations", Econometrica, 50: 1345-1370.

[37] Kydland, F. and C. Prescott (1989) "Cyclical Movements of Labor Input and its real Wage" Federal Reserve of Minneapolis, Research Department, Working Paper 413. 
[38] Kydland, F. and C. Prescott (1990) 'Business Cycles: Real Facts and a Monetary Myth', Federal Reserve Bank of Minneapolis, Quarterly Review, (Spring), p. 3-18.

[39] Mankiw, G. (1989), "Real Business Cycles: A New Keynesian Perspective", Journal of Economic Perspectives, 3(3): 79-90.

[40] McCullum, B. (1989), "Real Business Cycle Models" in Barro, R. Modern Business Cycle Theory, Cambridge, Ma.: Harvard University Press.

[41] Neftcy, S. (1984), “Are Economic Time Series Asymmetric over the Business Cycle?",Journal of Political Economy, 92(2): 307-328.

[42] Nelson, C., and C. Plosser (1982), "Trends and Random Walks in Macroeconomic Time Series," Journal of Monetary Economics 10: 139-162.

[43] Perron, P. (1989), "The Great Crach, The Oil Shock and the UNit Root Hypothesis", Econometrica, 57: 1361-1402.

[44] Pfann, G. (1991), "Employment and Business Cycle Asymmetries: A Data Based Study", Institute for Empirical Macroeconomics, Federal Reserve of Minneapolis, Discussion Paper 42.

[45] Plosser, C. (1989), "Understanding Real Business Cycles",Journal of Economic Perspective, $3(3): 51-77$.

[46] Priestley, M. B. (1981), Spectral Analysis and Time Series, New York, N.Y.: Academic Press.

[47] Prescott, E. (1986), "Theory ahead of Measurement" Federal Reserve Bank of Minneapolis, Quarterly Review, (Fall) p. 9-22.

[48] Sargent, T. and C. Sims (1977), "Business Cycle Modeling Without Pretending To Have Too Much A Priori Economic Theory," in A.Sims (ed.), New Methods in Business Cycle Research: Proceedings from a Conference Federal Reserve Bank of Minneapolis, Minneapolis, MN.

[49] Sargent, T. (1986), Macroeconomic Theory, New York, N.Y.: Academic Press. 
[50] Shiller, R. (1984), "Smoothness Priors and Nonlinear Regression", Journal of the American Statistical Association, 79:604-615.

[51] Sims, C. (1974), "Seasonality in Regression", Journal of the American Statistical Association, 69, 618-626.

[52] Singleton, K. (1988), "Econometric Issues in the Analysis of Equilibrium Business Cycle Models," Journal of Monetary Economics, 21: 361-386.

[53] Shapiro, S. and Wilks, M. (1972), "An Analysis of Variance Test for the Exponential Distribution (Complete Samples)" Technometrics, 14(2): 355-371.

[54] Stephens, M. (1978), "On the W test for Exponentiality with Origin Known", Technometrics, 20(1): 33-35.

[55] Stock, J. (1987), "Measuring Business Cycle Time", Journal of Political Economy, 95(6): $1240-1261$.

[56] Stock, J. and Watson, M. (1988), "Testing for Common Trends", Journal of the American Statistical Association, 83: 1097-1107

[57] Summers, L. (1986), "Some Skeptical Observations on Real Business Cycle Theory" Federal Reserve Bank of Minneapolis Quarterly Review 10 (Fall), 23-27.

[58] Warne, A. and Vredin. A. (1991), "Current Account and Macroeconomic Fluctuations: the Case of Sweden", forthcoming, Scandinavian Journal of Economics.

[59] Wabha, G. (1980), "Improper Prior, Spline Smoothing and the Problem of Guarding Against Model Errors in Regression",Journal of the Royal Statistical Society, Ser B, 40: 364-372.

[60] Watson, M. (1986), "Univariate Detrending Methods with Stochastic Trends," Journal of Monetary Economics, 18: 49-75.

[61] Watson, M. and R. Engle (1983), "Alternative Algorithms for the Estimation of Dynamic Factor, Mimic and Varying Coefficient Regression Models," Journal of Econometrics, 23: 385-400. 
[62] Wilcox, (1988), "What Do We Know About Consumption", Board of Governors of the Federal Reserve System, manuscript. 
Table 1

Standard Errors, as a percentage of GNP Standard Errors Seasonally adjusted data, 55,3-86,3 Sample

\begin{tabular}{|c|c|c|c|c|c|c|}
\hline Method & $\begin{array}{l}\text { GNP } \\
\text { Value }\end{array}$ & $\begin{array}{l}\text { Consumption } \\
\%\end{array}$ & $\begin{array}{l}\text { Investment } \\
\%\end{array}$ & $\begin{array}{l}\text { Hours } \\
\%\end{array}$ & $\begin{array}{l}\text { Wage } \\
\%\end{array}$ & $\begin{array}{l}\text { Capital } \\
\%\end{array}$ \\
\hline HP1600 & 1.76 & 0.49 & 2.82 & 1.06 & 0.78 & 0.61 \\
\hline HP4 & $0.55\left(^{*}\right)$ & $0.48\left(^{*}\right)$ & $2.70\left(^{*}\right)$ & $0.89\left(^{*}\right)$ & $0.78\left(^{*}\right)$ & $0.14\left(^{*}\right)$ \\
\hline HPOPT & $1.11\left(^{*}\right)$ & $0.46\left(^{*}\right)$ & $2.77\left({ }^{*}\right)$ & $1.06\left(^{*}\right)$ & $0.86\left(^{*}\right)$ & $0.33\left(^{*}\right)$ \\
\hline RW & $1.03\left(^{*}\right)$ & $0.51\left(^{*}\right)$ & $2.82\left(^{*}\right)$ & $0.91\left(^{*}\right)$ & $0.87\left(^{*}\right)$ & $0.63\left(^{*}\right)$ \\
\hline $\mathrm{BN}$ & $4.17\left(^{*}\right)$ & $0.68\left(^{*}\right)$ & $1.97\left(^{*}\right)$ & $0.69\left(^{*}\right)$ & $2.15\left(^{*}\right)$ & $1.36\left(^{*}\right)$ \\
\hline $\mathrm{UC}$ & $0.38\left(^{*}\right)$ & $0.34\left(^{*}\right)$ & $6.72\left(^{*}\right)$ & $4.14\left(^{*}\right)$ & 2.48 & $1.22\left(^{*}\right)$ \\
\hline LT & $4.03\left(^{*}\right)$ & $0.69\left(^{*}\right)$ & $2.16\left(^{*}\right)$ & $0.69\left(^{*}\right)$ & $1.80\left(^{*}\right)$ & $1.56\left(^{*}\right)$ \\
\hline POLY & $2.71\left(^{*}\right)$ & $0.54\left(^{*}\right)$ & $2.78\left(^{*}\right)$ & $0.88\left(^{*}\right)$ & $1.01\left(^{*}\right)$ & $0.65\left(^{*}\right)$ \\
\hline SEGM & $2.65\left(^{*}\right)$ & $0.52\left(^{*}\right)$ & $3.09\left(^{*}\right)$ & $1.01\left(^{*}\right)$ & $1.64\left(^{*}\right)$ & $0.97\left(^{*}\right)$ \\
\hline FD1 & 1.78 & 0.46 & 3.10 & 1.20 & $1.16\left(^{*}\right)$ & $1.41\left(^{*}\right)$ \\
\hline FD2 & $1.14\left(^{*}\right)$ & $0.44\left(^{*}\right)$ & $3.00\left(^{*}\right)$ & $1.16\left(^{*}\right)$ & 1.31 & $1.26\left(^{*}\right)$ \\
\hline HAMIL & $2.33\left(^{*}\right)$ & $1.53\left(^{*}\right)$ & $6.59\left({ }^{*}\right)$ & $1.97\left(^{*}\right)$ & $17.64\left(^{*}\right)$ & $4.42\left(^{*}\right)$ \\
\hline MLT & $4.09\left(^{*}\right)$ & $0.71(*)$ & $4.23\left(^{*}\right)$ & $0.70\left(^{*}\right)$ & $1.77\left({ }^{*}\right)$ & $1.54\left(^{*}\right)$ \\
\hline MFREQ & $5.65\left(^{*}\right)$ & $0.95\left(^{*}\right)$ & $2.06\left(^{*}\right)$ & $0.76\left(^{*}\right)$ & $3.36\left(^{*}\right)$ & $1.65\left(^{*}\right)$ \\
\hline COINT & $4.14\left(^{*}\right)$ & $0.71\left(^{*}\right)$ & $3.96\left(^{*}\right)$ & $0.75\left(^{*}\right)$ & $1.78\left(^{*}\right)$ & $1.30\left(^{*}\right)$ \\
\hline
\end{tabular}

Note: A "*" indicates that the null hypothesis that the variance of the cyclical component of the series is identical to the variance of the cyclical component obtained with HP1600 is rejected at the $95 \%$ confidence. 
Table 2

Skewness

Seasonally adjusted data, 55,3-86,3 Sample

\begin{tabular}{lllllll}
\hline Method & GNP & Consumption & Investment & Hours & Wage & Capital \\
\hline HP1600 & -0.024 & -0.034 & -0.367 & -0.400 & 0.172 & -0.247 \\
HP4 & 0.174 & 0.196 & 0.058 & 0.303 & 0.044 & 0.082 \\
HPOPT & -0.125 & 0.178 & -0.509 & -0.247 & 0.169 & -0.247 \\
RW & -0.045 & -0.322 & -0.367 & -0.328 & -0.156 & -0.351 \\
BN & -0.060 & -0.237 & -0.478 & -0.374 & -0.087 & -0.244 \\
UC & -0.028 & -0.207 & -0.342 & -0.179 & -0.071 & -0.220 \\
LT & -0.114 & -0.253 & -0.460 & -0.385 & -0.112 & -0.320 \\
POLY & -0.227 & -0.282 & -0.506 & -0.638 & -0.107 & -0.246 \\
SEGM & 0.086 & -0.322 & -0.459 & -0.350 & $-4.626\left(^{*}\right)$ & $4.490\left(^{*}\right)$ \\
FD1 & -0.048 & 0.090 & -0.316 & -0.310 & -0.193 & -0.187 \\
FD2 & 0.156 & 0.056 & -0.104 & -0.252 & 0.128 & 0.584 \\
HAMIL & 0.256 & -0.484 & -0.556 & -0.360 & 0.052 & $-4.582\left(^{*}\right)$ \\
& & & & & & \\
MLT & -0.135 & -0.255 & -0.479 & -0.366 & -0.112 & -0.320 \\
MFREQ & 0.107 & -0.249 & -0.330 & -0.450 & 0.080 & 0.226 \\
COINT & -0.146 & -0.239 & -0.423 & -0.376 & 0.030 & -0.226 \\
\hline
\end{tabular}

Note: A "*" indicates that the null hypothesis that the skewness coefficient is identical to the skewness coefficient obtained under normality is rejected at the $95 \%$ confidence. 
Table 3

Excess Kurtosis

Seasonally adjusted data, 55,3-86,3 Sample

\begin{tabular}{lllllll}
\hline Method & GNP & Consumption & Investment & Hours & Wage & Capital \\
\hline HP1600 & 0.066 & -0.077 & 1.382 & 0.953 & 0.458 & 0.949 \\
HP4 & -0.131 & -0.616 & 0.512 & 0.455 & 0.115 & 0.395 \\
HPOPT & 0.080 & 0.291 & 1.135 & 0.590 & 0.115 & 0.325 \\
RW & -0.222 & -0.220 & 0.788 & 0.111 & 0.061 & 0.660 \\
BN & 0.087 & 0.135 & 1.153 & 0.578 & 0.103 & 0.896 \\
UC & -0.153 & -0.568 & 0.781 & -0.050 & 0.020 & 0.758 \\
LT & 0.206 & 0.162 & 1.089 & 0.938 & 0.249 & 1.051 \\
POLY & 0.093 & -0.051 & 1.156 & 1.092 & 0.394 & 0.906 \\
SEGM & 0.438 & 0.428 & 1.002 & 0.744 & $38.15\left(^{*}\right)$ & $38.08\left(^{*}\right)$ \\
FD1 & -0.068 & 0.490 & 1.336 & 0.649 & 0.440 & 0.517 \\
FD2 & 0.464 & -0.265 & 0.234 & -0.052 & 0.385 & 1.570 \\
HAMIL & 0.314 & 1.063 & 0.955 & 1.615 & 0.027 & $32.74\left(^{*}\right)$ \\
& & & & & & \\
MLT & 0.186 & 0.194 & 0.929 & 0.716 & 0.249 & 1.051 \\
MFREQ & 0.013 & 0.000 & 0.803 & 0.775 & 1.301 & 0.538 \\
COINT & -0.065 & 0.064 & 0.906 & 0.561 & 0.219 & 0.854 \\
\hline
\end{tabular}

Note: A "*" indicates that the null hypothesis that the value of the excess kurtosis is in each cell is identical to the value appearing under normality $(=0.0)$ is rejected at the $95 \%$ confidence. 


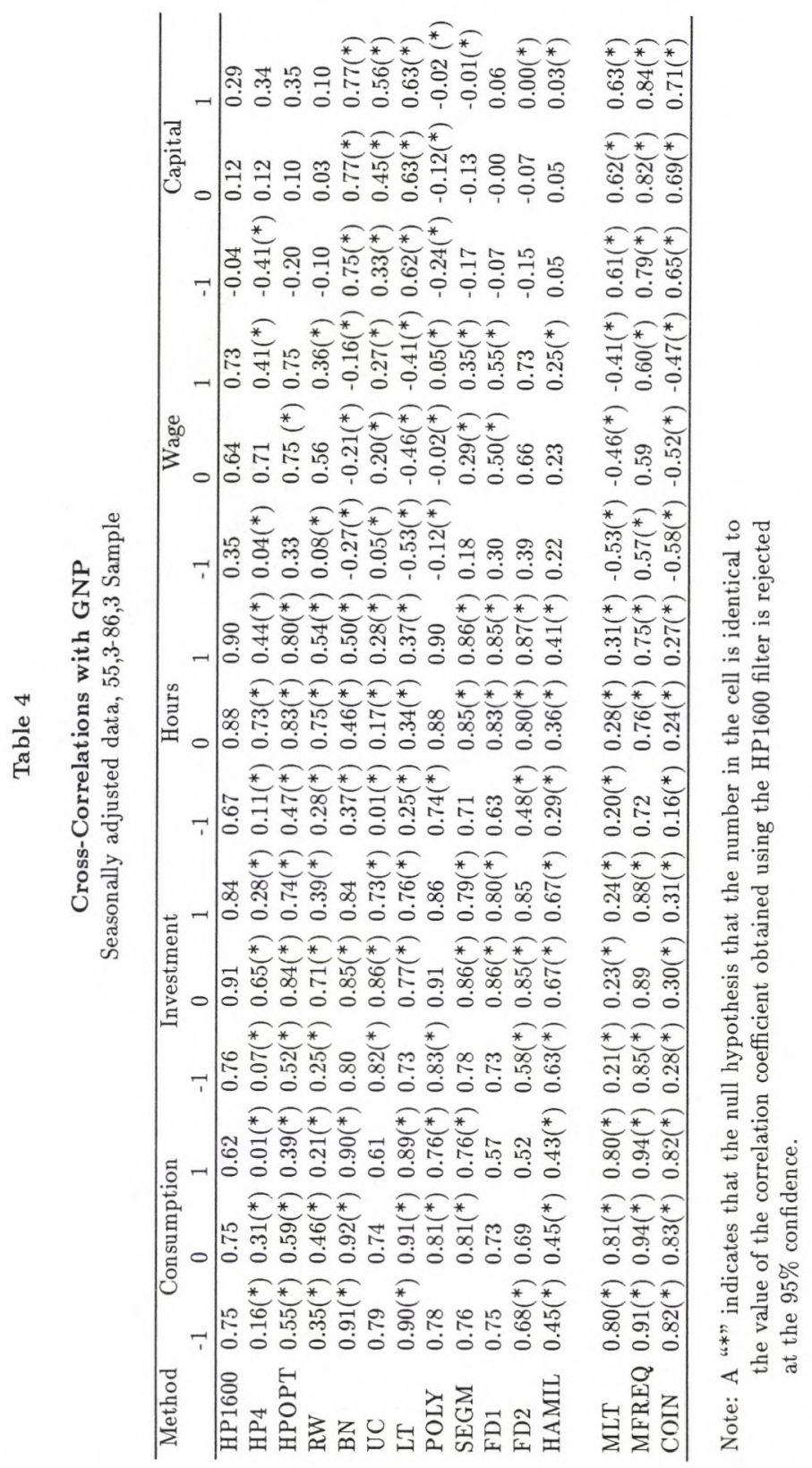


Table 5

\section{Business Cycle Chronology Seasonally adjusted data, 55,3-86,3 Sample}

\begin{tabular}{lll}
\hline & & Turning Points \\
Method & Throughs & Peaks \\
\hline HP1600 & $56,3\left(^{*}\right) ; 59,1 ; 61,4 ; 65,2 ; 72,2$ & 57,$4 ; 60,3 ; 62,4 ; 69,4 ; 74,3 ;$ \\
& 77,$3 ; 80,4 ; 84,1\left(^{*}\right)$ & 80,$2 ; 81,4$ \\
HP4 & $56,3\left(^{*}\right) ; 58,4 ; 60,1 ; 61,4 ; 64,1 ; 65,4 ;$ & 58,$1 ; 59,3 ; 60,4 ; 62,4 ; 64,4 ; 66,4 ; 70,1$ \\
& 68,$2 ; 71,1 ; 73,1 ; 75,3 ; 77,2 ; 78,2 ; 79,3 ;$ & 71,$4 ; 75,1 ; 76,3 ; 77,4 ; 79,1 ; 80,2 ; 82,3 ;$ \\
& 81,$1 ; 84,1$ & $84,4\left(^{*}\right)$ \\
HPOPT & $56,3\left(^{*}\right) ; 58,4 ; 61,4 ; 64,1 ; 65,4 ; 68,2 ;$ & 57,$4 ; 60,4 ; 62,4 ; 64,3 ; 66,4 ; 70,1$ \\
& 72,$2 ; 76,1 ; 77,2 ; 78,2 ; 81,1 ; 83,4$ & 74,$3 ; 76,3 ; 77,4 ; 80,2 ; 82,1 ; 86,2\left(^{*}\right)$ \\
RW & 58,$2 ; 72,1 ; 75,2 ; 82,4\left(^{*}\right)$ & 57,$4 ; 69,4 ; 74,3 ; 81,4$ \\
BN & $56,3\left(^{*}\right) ; 59,1 ; 62,1 ; 72,3 ; 76,2 ; 81,2 ; 83,4\left(^{*}\right)$ & 58,$2 ; 61,1 ; 72,1 ; 75,2 ; 80,4 ; 82,4$ \\
UC & 60,$3 ; 76,4 ; 84,3\left(^{*}\right)$ & 76,$1 ; 83,2$ \\
LT & 64,$1 ; 76,1 ; 77,1$ & $56,3\left(^{*}\right) ; 75,1 ; 76,3 ; 80,2\left(^{*}\right)$ \\
POLY & $56,3\left(^{*}\right), 64,1 ; 72,2 ; 78,2 ; 84,1\left(^{*}\right)$ & 57,$4 ; 70,2 ; 74,3 ; 80,2$ \\
SEGM & $56,3\left(^{*}\right) ; 65,1 ; 73,1 ; 77,2 ; 84,1\left(^{*}\right)$ & 57,$4 ; 70,1 ; 74,3 ; 81,4$ \\
FD1 & $56,3\left(^{*}\right) ; 58,4 ; 61,4 ; 65,3 ; 72,2 ; 78,2 ;$ & 57,$4 ; 60,4 ; 62,4 ; 69,4 ; 74,4 ; 80,2 ;$ \\
& 80,$4 ; 83,4$ & 81,$4 ; 86,1\left(^{*}\right)$ \\
FD2 & $56,3\left(^{*}\right) ; 59,1 ; 61,4 ; 63,4 ; 65,3 ; 68,3 ;$ & 57,$4 ; 60,4 ; 62,3 ; 64,4 ; 66,4 ; 70,2 ;$ \\
& 72,$3 ; 75,4 ; 78,2 ; 81,1 ; 83,4$ & 74,$3 ; 77,4 ; 79,1 ; 82,1 ; 85,1\left(^{*}\right)$ \\
HAMIL & 65,$4 ; 72,1 ; 76,1 ; 77,1$ & $56,3\left(^{*}\right) ; 69,4 ; 75,1 ; 76,3 ; 80,2\left(^{*}\right)$ \\
& & \\
MLT & 64,$1 ; 77,1$ & $56,3\left(^{*}\right) ; 74,4 ; 80,2\left(^{*}\right)$ \\
MFREQ & $56,3\left(^{*}\right) ; 65,2 ; 81,1\left(^{*}\right)$ & 58,$1 ; 74,3$ \\
COINT & 65,$4 ; 72,4$ & $56,3\left(^{*}\right) ; 70,1 ; 74,1\left(^{*}\right)$ \\
& & \\
NBER & 58,$2 ; 61,1 ; 70,4 ; 75,1 ; 80,3 ; 82,4$ & 57,$3 ; 60,2 ; 69,4 ; 73,4 ; 80,1 ; 81,3$ \\
CLI & 58,$1 ; 60,4 ; 70,4 ; 75,1 ; 80,2 ; 82,1$ & 59,$2 ; 69,2 ; 73,1 ; 79,1 ; 81,2$ \\
\hline
\end{tabular}

Note: A turning point is defined as the first of at least two successive increases (declines) in the demeaned growth rate of GNP. NBER refers to the NBER dating of business cycles. CLI refers to the chronology of turning points compiled from the composite index of leading indicators and it is taken from the Business Condition Digest, chart $1 \mathrm{~A}$. A "*" indicates that the previous (or next) turning point is censored. 
Table 6

Test for Duration Dependences Seasonally adjusted data, 55,3-86,3 Sample

\begin{tabular}{|c|c|c|c|c|}
\hline Method & Expansion & Contraction & Trough to Through & Peak to Peak \\
\hline \multirow[t]{2}{*}{ HP1600 } & 0.57 & 0.50 & 0.98 & 0.42 \\
\hline & (9) & (8) & $(9)$ & $(8)$ \\
\hline \multirow[t]{2}{*}{ HP4 } & 0.32 & 0.33 & 0.34 & 0.19 \\
\hline & (16) & (16) & (16) & (17) \\
\hline \multirow[t]{2}{*}{ HPOPT } & 0.56 & 0.75 & 0.42 & 0.31 \\
\hline & (13) & (13) & (13) & (14) \\
\hline \multirow[t]{2}{*}{ RW } & 0.54 & 0.32 & 0.45 & 0.70 \\
\hline & (6) & (5) & $(6)$ & $(5)$ \\
\hline \multirow[t]{2}{*}{$\mathrm{BN}$} & 0.56 & 0.20 & 0.14 & 0.51 \\
\hline & $(8)$ & $(7)$ & $(8)$ & $(8)$ \\
\hline \multirow[t]{2}{*}{ UC } & $0.18\left(^{*}\right)$ & $0.19\left(^{*}\right)$ & 0.35 & 0.50 \\
\hline & $(4)$ & (3) & $(4)$ & $(4)$ \\
\hline \multirow[t]{2}{*}{ LT } & 0.35 & 0.35 & 0.19 & 0.18 \\
\hline & (4) & $(5)$ & $(5)$ & $(5)$ \\
\hline \multirow[t]{2}{*}{ POLY } & 0.67 & 0.24 & 0.23 & 0.53 \\
\hline & $(6)$ & $(5)$ & $(6)$ & $(6)$ \\
\hline \multirow[t]{2}{*}{ SEGM } & 0.20 & 0.14 & 0.33 & 0.26 \\
\hline & $(6)$ & $(5)$ & $(6)$ & $(6)$ \\
\hline \multirow[t]{2}{*}{ FD1 } & 0.19 & 0.25 & 0.33 & 0.12 \\
\hline & $(9)$ & $(9)$ & $(9)$ & (10) \\
\hline \multirow[t]{2}{*}{ FD2 } & 0.18 & 0.15 & 0.14 & 0.31 \\
\hline & (12) & (12) & (12) & (13) \\
\hline \multirow[t]{2}{*}{ HAMIL } & 0.16 & 0.14 & 0.28 & 0.19 \\
\hline & (5) & $(6)$ & $(6)$ & $(6)$ \\
\hline \multirow[t]{2}{*}{ MLT } & 0.48 & $0.16\left(^{*}\right)$ & 0.20 & 0.24 \\
\hline & (3) & (4) & (4) & (4) \\
\hline \multirow[t]{2}{*}{ MFREQ } & $0.08\left(^{*}\right)$ & $0.11\left(^{*}\right)$ & 0.26 & $0.17\left(^{*}\right)$ \\
\hline & $(4)$ & (3) & $(4)$ & (4) \\
\hline \multirow[t]{2}{*}{ COINT } & $0.07\left(^{*}\right)$ & $0.07\left(^{*}\right)$ & 0.26 & 0.20 \\
\hline & (3) & (4) & $(4)$ & $(4)$ \\
\hline
\end{tabular}

Note: The table reports are the values of the Shapiro-Wilks (1972) statistics modified by Stephens (1978) to take into account two quarters of minimum duration. A "*" indicates that the hypothesis of no duration dependence is rejected at the $95 \%$ confidence. In parenthesis the number of samples available for each cell. 
Table 7

Standard Errors, as a percentage of GNP Standard Errors Seasonally nonadjusted data

\begin{tabular}{|c|c|c|c|c|c|c|}
\hline Method & $\begin{array}{l}\text { GNP } \\
\text { Value }\end{array}$ & $\begin{array}{l}\text { Consumption } \\
\%\end{array}$ & $\begin{array}{l}\text { Investment } \\
\%\end{array}$ & $\begin{array}{l}\text { Hours } \\
\%\end{array}$ & $\begin{array}{l}\text { Wage } \\
\%\end{array}$ & $\begin{array}{l}\text { Capital } \\
\%\end{array}$ \\
\hline HP1600 & 3.32 & 0.94 & 2.26 & 0.20 & 0.25 & 0.25 \\
\hline HP4 & 2.91 & 1.00 & $2.02\left(^{*}\right)$ & $0.05\left(^{*}\right)$ & $0.23\left(^{*}\right)$ & $0.14\left(^{*}\right)$ \\
\hline HPOPT & 3.17 & 0.97 & 2.09 & $0.09\left(^{*}\right)$ & 0.24 & $0.16\left(^{*}\right)$ \\
\hline $\mathrm{RW}$ & $5.53\left({ }^{*}\right)$ & $1.07(*)$ & $2.04\left(^{*}\right)$ & $0.19\left(^{*}\right)$ & 0.17 & $0.09\left(^{*}\right)$ \\
\hline $\mathrm{BN}$ & 2.96 & $1.82\left(^{*}\right)$ & $1.96\left(^{*}\right)$ & $11.75\left(^{*}\right)$ & $0.20\left(^{*}\right)$ & $2.89\left(^{*}\right)$ \\
\hline $\mathrm{UC}$ & $0.69\left(^{*}\right)$ & $0.81\left(^{*}\right)$ & $6.50\left(^{*}\right)$ & $1.92\left(^{*}\right)$ & $0.70\left(^{*}\right)$ & $0.87\left(^{*}\right)$ \\
\hline LT & $10.97\left(^{*}\right)$ & $1.18\left(^{*}\right)$ & $1.36\left(^{*}\right)$ & $1.93\left({ }^{*}\right)$ & $0.08\left(^{*}\right)$ & $0.26\left(^{*}\right)$ \\
\hline POLY & $4.69\left(^{*}\right)$ & $0.92\left(^{*}\right)$ & $1.91\left(^{*}\right)$ & $0.35\left(^{*}\right)$ & 0.17 & $0.30\left(^{*}\right)$ \\
\hline SEGM & $5.35\left(^{*}\right)$ & $0.91\left(^{*}\right)$ & $2.12\left(^{*}\right)$ & $1.74\left(^{*}\right)$ & 0.16 & $0.43\left(^{*}\right)$ \\
\hline FD1 & 3.43 & 1.00 & 2.13 & $0.98\left(^{*}\right)$ & 0.24 & $0.37(*)$ \\
\hline FD2 & $1.48\left(^{*}\right)$ & $0.92\left(^{*}\right)$ & $2.11\left(^{*}\right)$ & $1.44\left(^{*}\right)$ & $0.25\left(^{*}\right)$ & 0.53 \\
\hline MLT & $4.75\left(^{*}\right)$ & $1.26\left(^{*}\right)$ & $1.84\left(^{*}\right)$ & $0.61\left(^{*}\right)$ & $1.67\left(^{*}\right)$ & $0.20\left(^{*}\right)$ \\
\hline MFREQ & $13.12\left(^{*}\right)$ & $1.03\left(^{*}\right)$ & $1.10\left(^{*}\right)$ & $0.78\left(^{*}\right)$ & $0.85\left(^{*}\right)$ & $0.09\left(^{*}\right)$ \\
\hline
\end{tabular}

Note: The sample is $46,1-85,4$ for GNP, Consumption, Investment and Capital and $64,1-85,4$ for Hours and Wage. A "**" indicates that the null hypothesis that the variance of the cyclical component of the series is identical to the variance of the cyclical component of the series obtained using the HP1600 filter is rejected at the $95 \%$ confidence. 
Table 8

Skewness

Seasonally nonadjusted data

\begin{tabular}{lllllll}
\hline Method & GNP & Consumption & Investment & Hours & Wage & Capital \\
\hline HP1600 & 0.211 & 1.095 & -0.264 & -0.408 & -0.179 & 0.149 \\
HP4 & 0.160 & -0.706 & -0.007 & 0.101 & -0.114 & -0.050 \\
HPOPT & 0.184 & 0.513 & -0.264 & -0.482 & -0.165 & 0.128 \\
RW & -0.379 & 0.322 & -0.497 & -0.812 & -0.235 & -0.252 \\
BN & 0.373 & 0.080 & -0.155 & 0.532 & -0.117 & 0.283 \\
UC & -0.213 & 0.492 & -0.650 & -1.015 & -0.115 & -0.185 \\
LT & -0.214 & 0.497 & -0.349 & -0.623 & -0.276 & -0.228 \\
POLY & -0.159 & 0.486 & -0.245 & -0.426 & -0.122 & -0.120 \\
SEGM & -0.723 & -1.888 & -0.171 & $-10.03\left(^{*}\right)$ & -0.354 & $-3.69\left(^{*}\right)$ \\
FD1 & -0.345 & 0.260 & -0.191 & $8.00\left(^{*}\right)$ & -0.210 & -0.094 \\
FD2 & 0.123 & -0.097 & -0.015 & -0.088 & -0.127 & 0.036 \\
& & & & & & \\
MLT & 0.145 & 1.284 & -0.258 & -0.228 & -0.691 & -0.276 \\
MFREQ & -0.245 & 0.643 & -0.147 & -0.466 & -0.013 & -0.344 \\
\hline
\end{tabular}

Note: The sample is $46,1-85,4$ for GNP, Consumption, Investment and Capital and 64,1-85,4 for Hours and Productivity. A "*" indicates that the null hypothesis that the skewness coefficient is identical to the skewness coefficient obtained under normality is rejected at the $95 \%$ confidence. 
Table 9

Excess Kurtosis

Seasonally nonadjusted data

\begin{tabular}{lllllll}
\hline Method & GNP & Consumption & Investment & Hours & Wage & Capital \\
\hline HP1600 & -0.560 & $4.829\left(^{*}\right)$ & 0.607 & $1.975\left(^{*}\right)$ & -0.520 & -0.002 \\
HP4 & 0.042 & $3.057\left(^{*}\right)$ & 0.700 & $2.011\left(^{*}\right)$ & -0.344 & 0.409 \\
HPOPT & -0.775 & $2.732\left(^{*}\right)$ & 0.628 & $2.750\left(^{*}\right)$ & -0.377 & 0.236 \\
RW & 1.045 & $2.362\left(^{*}\right)$ & 1.204 & $2.465\left(^{*}\right)$ & -0.736 & 0.065 \\
BN & 0.735 & 1.092 & 0.889 & 1.281 & -0.255 & -0.255 \\
UC & 0.798 & $2.815\left(^{*}\right)$ & 1.367 & $3.233\left(^{*}\right)$ & -0.707 & -0.217 \\
LT & 0.476 & $2.870\left(^{*}\right)$ & 0.915 & 1.799 & -0.813 & 0.681 \\
POLY & 0.116 & 1.773 & 0.882 & 1.386 & -0.604 & 0.234 \\
SEGM & $2.309\left(^{*}\right)$ & $15.90\left(^{*}\right)$ & 1.101 & $114.9\left(^{*}\right)$ & -0.731 & $24.74\left(^{*}\right)$ \\
FD1 & $6.537\left(^{*}\right)$ & $14.24\left(^{*}\right)$ & 1.187 & $84.41\left(^{*}\right)$ & -0.529 & 0.043 \\
FD2 & -0.552 & 0.344 & 0.125 & 0.767 & -0.341 & 0.479 \\
& & & & & & \\
MLT & 0.842 & $5.869\left(^{*}\right)$ & 0.603 & 0.681 & 1.774 & -0.813 \\
MFREQ & 0.132 & 1.465 & 0.411 & 0.734 & 0.576 & -0.612 \\
\hline
\end{tabular}

Note: The sample is $46,1-85,4$ for GNP, Consumption, Investment and Capital and 64,1-85,4 for Hours and Productivity. A "** indicates that the null hypothesis that the value of the excess kurtosis is identical to the value appearing under normality $(=0.0)$ is rejected at the $95 \%$ confidence. 


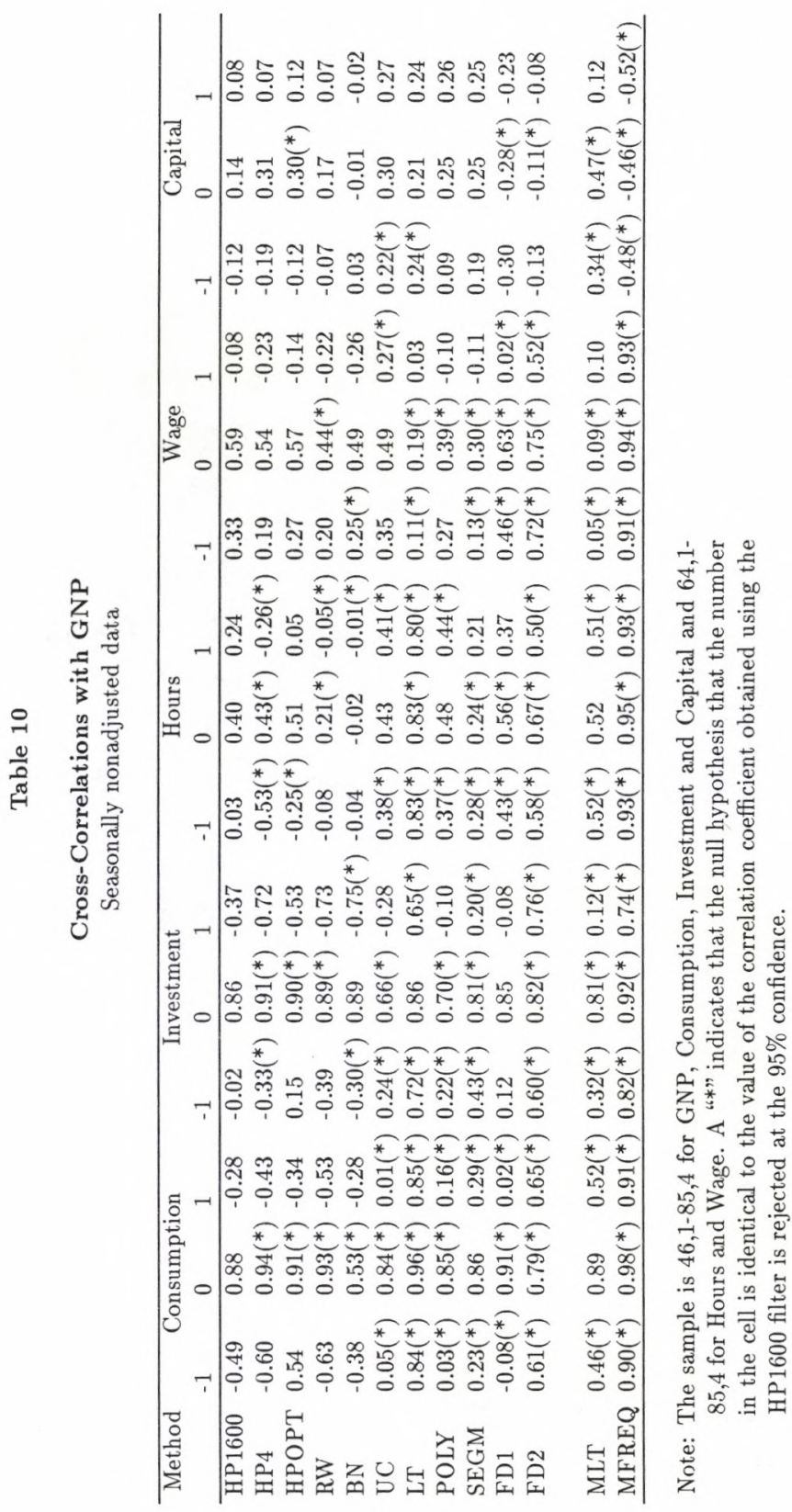



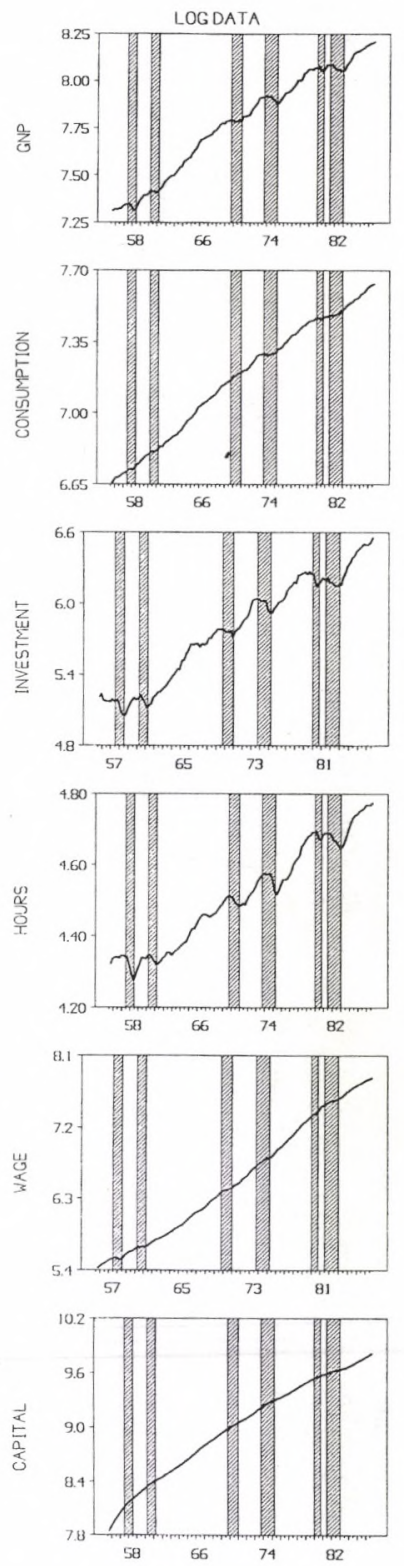
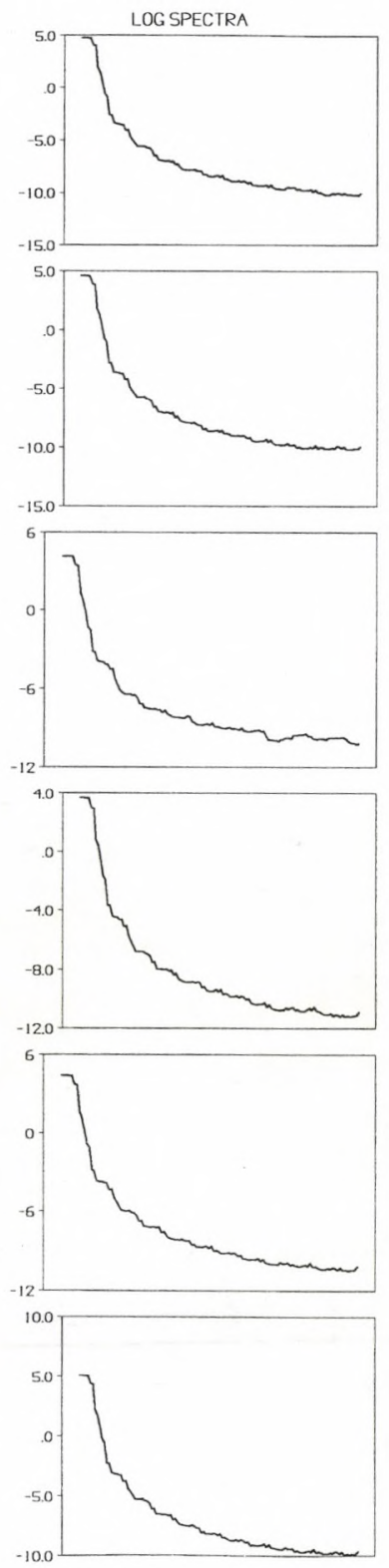

Figure 1
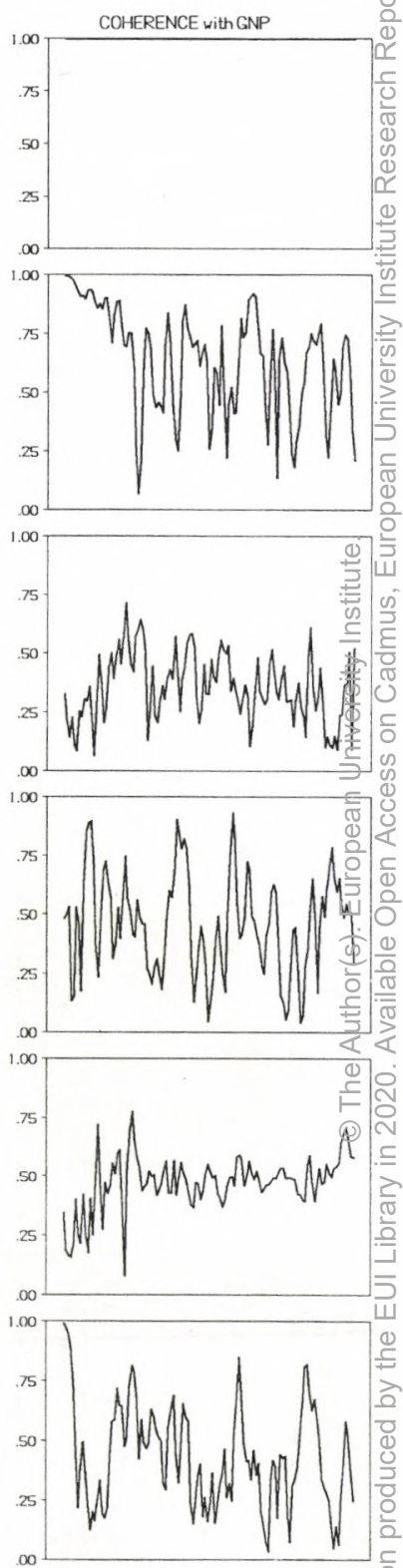

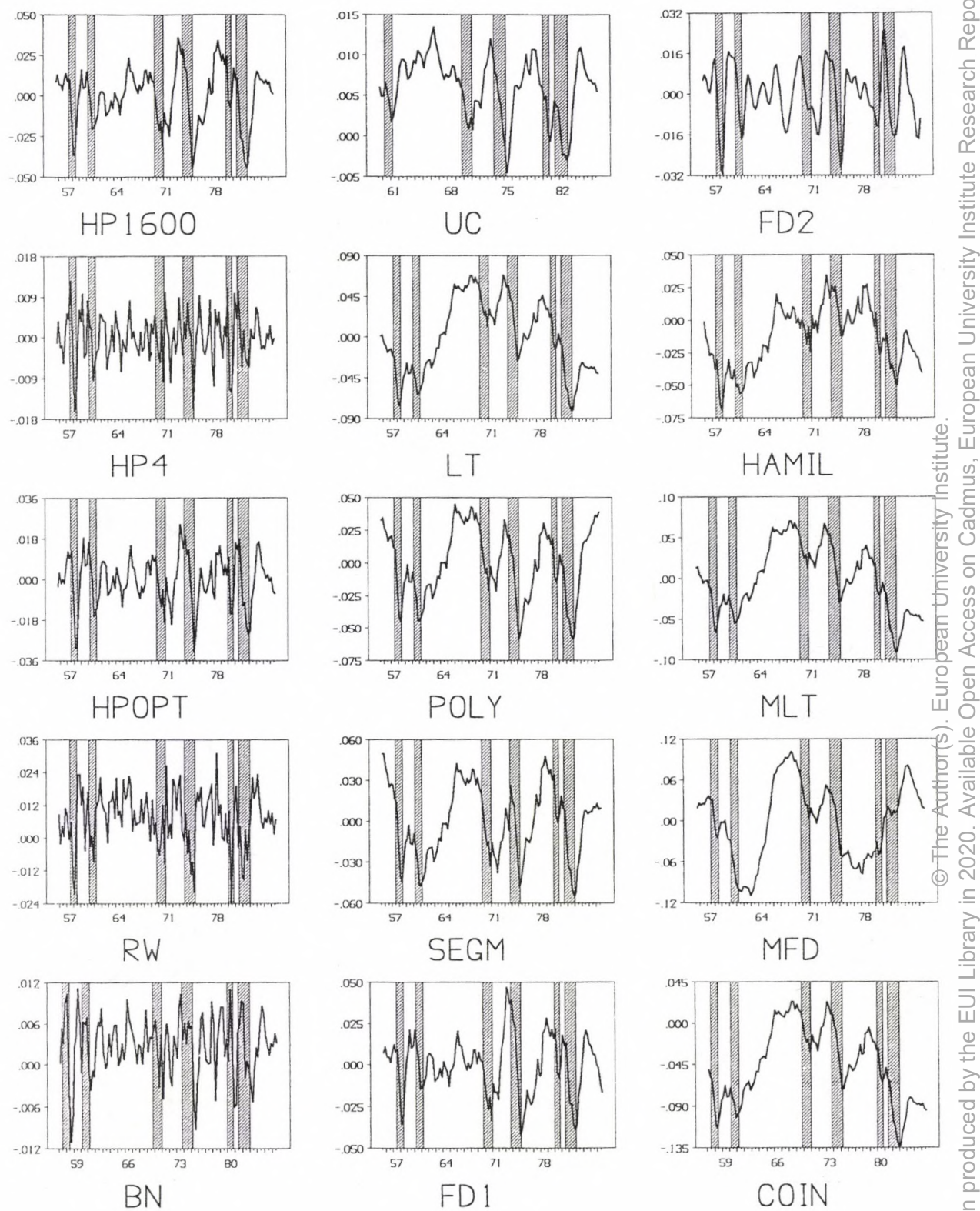

Figure 2 

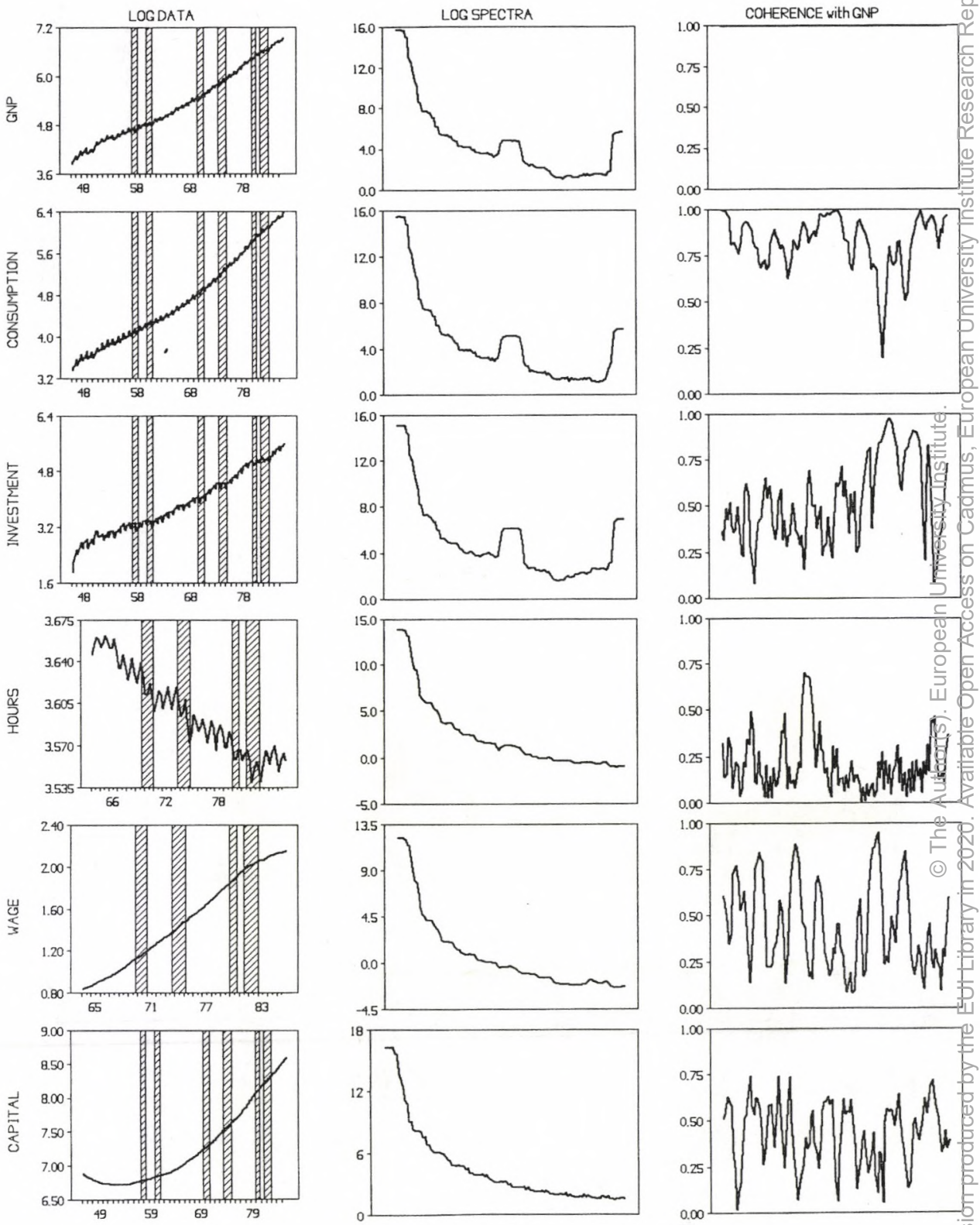

Figure 3 

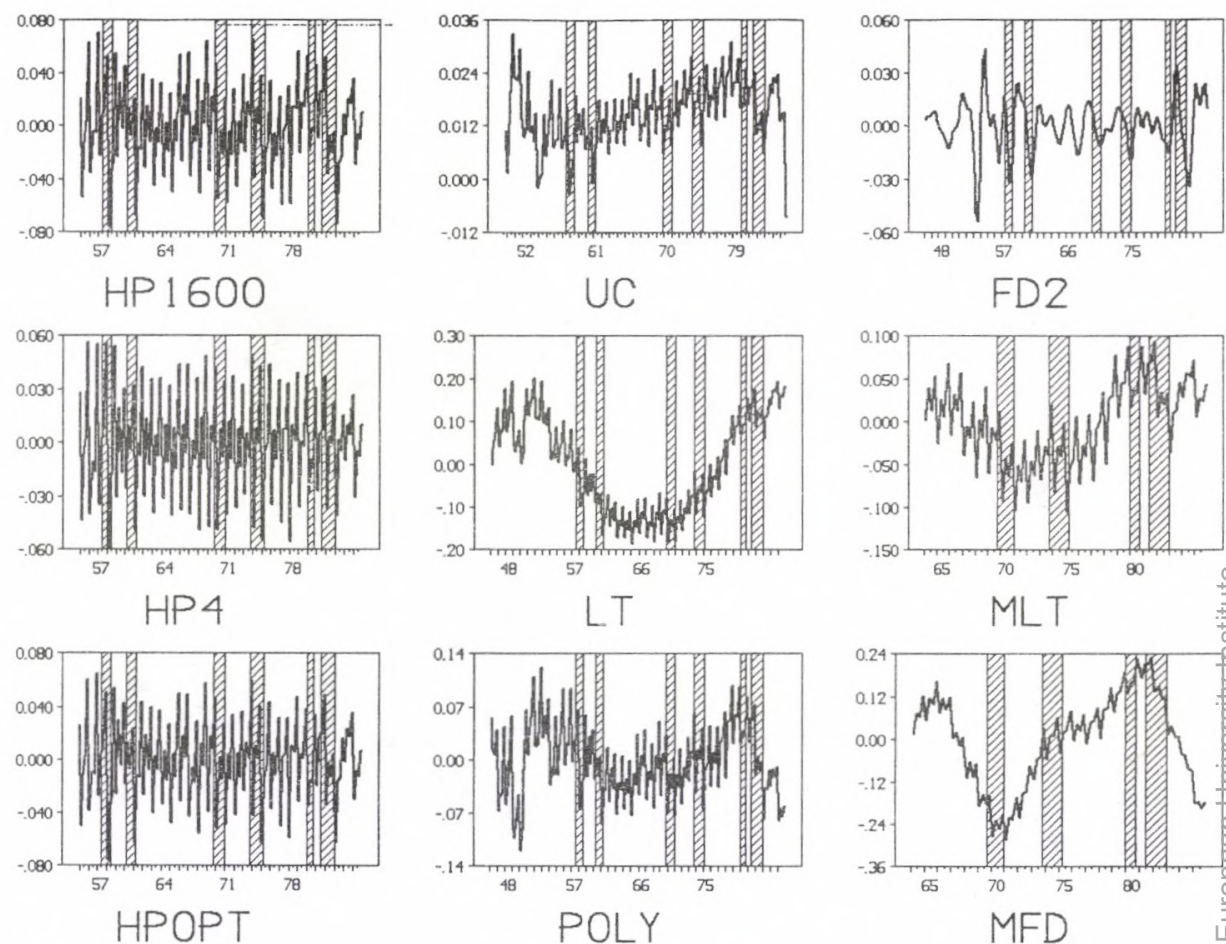

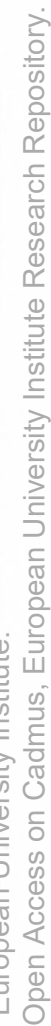
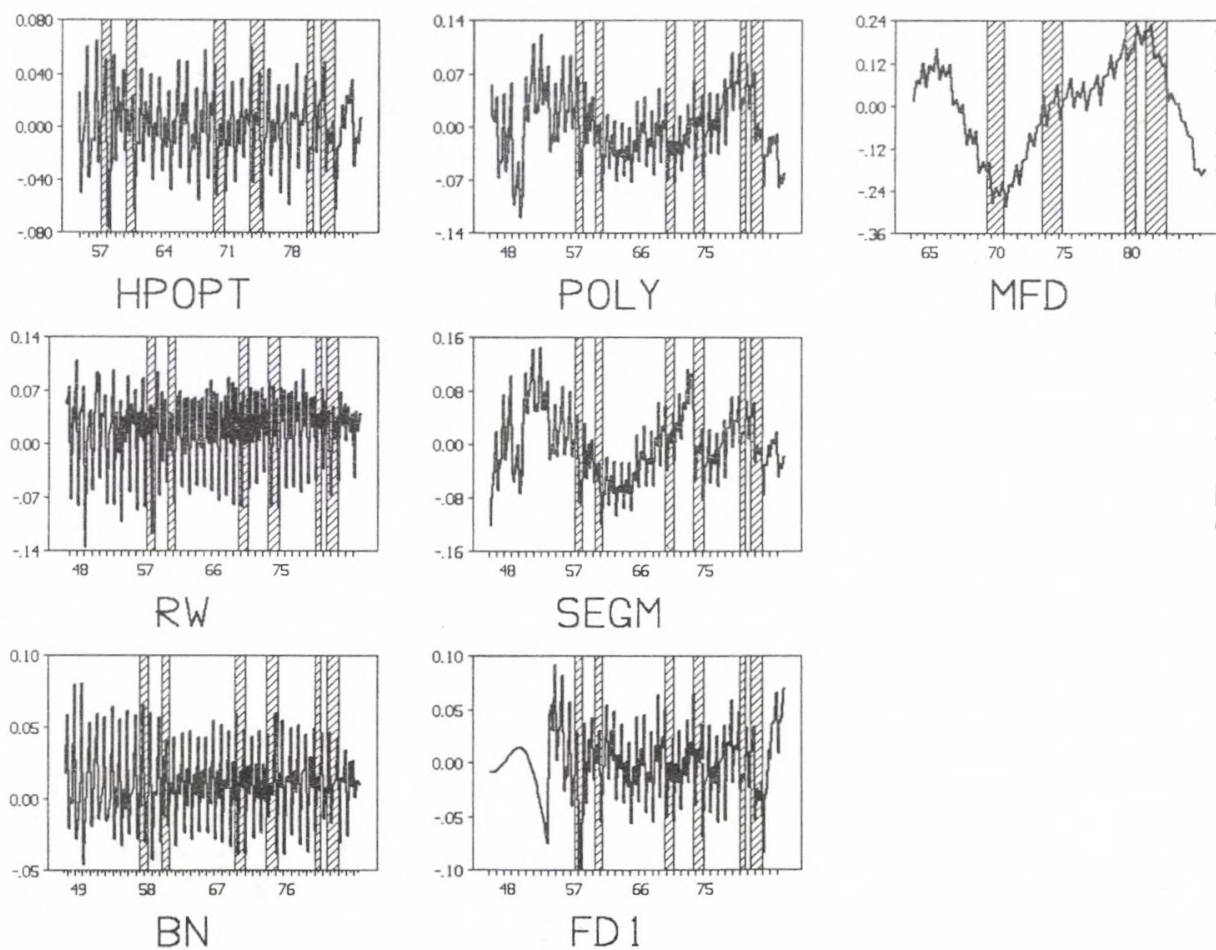


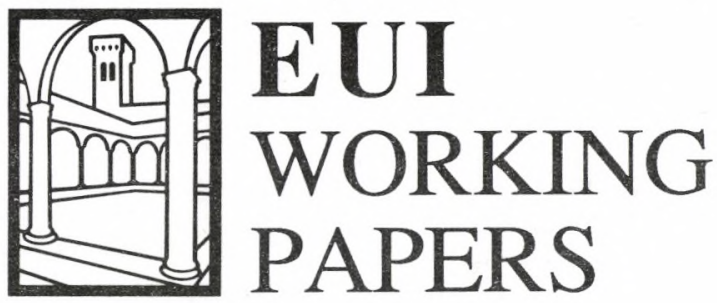

EUI Working Papers are published and distributed by the European University Institute, Florence

Copies can be obtained free of charge - depending on the availability of stocks - from:

The Publications Officer

European University Institute

Badia Fiesolana

I-50016 San Domenico di Fiesole (FI)

Italy

Please use order form overleaf 


\section{Publications of the European University Institute}

To

The Publications Officer

European University Institute

Badia Fiesolana

I-50016 San Domenico di Fiesole (FI)

Italy

From Name

Address . . . . . . . . . . .

$\square$ Please send me a complete list of EUI Working Papers

$\square$ Please send me a complete list of EUI book publications

$\checkmark$ Please send me the EUI brochure Academic Year 1992/93

Please send me the following EUI Working Paper(s):

No, Author

Title:

No, Author

Title:

No, Author

Title:

No, Author

Title:

Date

Signature 


\section{Working Papers of the Department of Economics Published since 1989}

$89 / 370$

B. BENSAID/ R.J. GARY-BOBO/

S. FEDERBUSCH

The Strategic Aspects of Profit Sharing in the Industry

$89 / 374$

Francisco S. TORRES

Small Countries and Exogenous Policy Shocks

$89 / 375$

Renzo DAVIDDI

Rouble Convertibility: A Realistic Target

$89 / 377$

Elettra AGLIARDI

On the Robustness of Contestability Theory

$89 / 378$

Stephen MARTIN

The Welfare Consequences of Transaction Costs in Financial Markets

$89 / 381$

Susan SENIOR NELLO

Recent Developments in Relations Between the EC and Eastern Europe

$89 / 382$

Jean GABSZEWICZ/ Paolo GARELLA/

Charles NOLLET

Spatial Price Competition With Uninformed Buyers

\section{$89 / 383$}

Benedetto GUI

Beneficiary and Dominant Roles in

Organizations: The Case of Nonprofits

\section{$89 / 384$}

Agustín MARAVALL/ Daniel PEÑA Missing Observations, Additive Outliers and Inverse Autocorrelation Function

\section{$89 / 385$}

Stephen MARTIN

Product Differentiation and Market Performance in Oligopoly

\section{$89 / 386$}

\section{Dalia MARIN}

Is the Export-Led Growth Hypothesis Valid for Industrialized Countries?
$89 / 387$

Stephen MARTIN

Modeling Oligopolistic Interaction

$89 / 388$

Jean-Claude CHOURAQUI

The Conduct of Monetary Policy: What have we Learned From Recent Experience

$89 / 390$

Corrado BENASSI

Imperfect Information and Financial Markets: A General Equilibrium Model

\section{$89 / 394$}

Serge-Christophe KOLM

Adequacy, Equity and Fundamental Dominance: Unanimous and Comparable Allocations in Rational Social Choice, with Applications to Marriage and Wages

$89 / 395$

Daniel HEYMANN/ Axel LEUONHUFVUD

On the Use of Currency Reform in Inflation Stabilization

$89 / 400$

Robert J. GARY-BOBO

On the Existence of Equilibrium Configurations in a Class of Asymmetric Market Entry Games *

$89 / 402$

Stephen MARTIN

Direct Foreign Investment in The United States

$89 / 413$

Francisco S. TORRES

Portugal, the EMS and 1992: Stabilization and Liberalization

$89 / 416$

Joerg MAYER

Reserve Switches and Exchange-Rate Variability:

The Presumed Inherent Instability of the Multiple Reserve-Currency System

$89 / 417$

José P. ESPERANÇA/ Neil KAY

Foreign Direct Investment and Competition in the Advertising Sector: The Italian Case 
$89 / 418$

Luigi BRIGHI/ Mario FORNI

Aggregation Across Agents in Demand Systems

$89 / 420$

Corrado BENASSI

A Competitive Model of Credit Intermediation

$89 / 422$

Marcus MILLER/ Mark SALMON

When does Coordination pay?

$89 / 423$

Marcus MILLER/ Mark SALMON/

Alan SUTHERLAND

Time Consistency, Discounting and the Returns to Cooperation

\section{$89 / 424$}

Frank CRITCHLEY/ Paul MARRIOTT/

Mark SALMON

On the Differential Geometry of the Wald Test with Nonlinear Restrictions

\section{$89 / 425$}

Peter J. HAMMOND

On the Impossibility of Perfect Capital Markets

\section{$89 / 426$}

Peter J. HAMMOND

Perfected Option Markets in Economies with Adverse Selection

\section{$89 / 427$}

Peter J. HAMMOND

Irreducibility, Resource Relatedness, and Survival with Individual Non-Convexities

$$
* * *
$$

ECO No. $90 / 1^{\circ}$

Tamer BASAR and Mark SALMON

Credibility and the Value of Information

Transmission in a Model of Monetary Policy and Inflation

\section{ECO No. $90 / 2$}

Horst UNGERER

The EMS - The First Ten Years

Policies - Developments - Evolution

ECO No. $90 / 3$

Peter J. HAMMOND

Interpersonal Comparisons of Utility: Why and how they are and should be made

** Please note: As from January 1990, the EUI Working Papers Series is divided into six sub-series, each series will be numbered individually (e.g. EUI Working Paper LAW No. 90/1).
ECO No. $90 / 4$

Peter J. HAMMOND

A Revelation Principle for (Boundedly) Bayesian Rationalizable Strategies

ECO No. $90 / 5$

Peter J. HAMMOND

Independence of Irrelevant Interpersonal

Comparisons

ECO No. 90/6

Hal R. VARIAN

A Solution to the Problem of Externalities and Public Goods when Agents are Well-Informed

ECO No. $90 / 7$

Hal R. VARIAN

Sequential Provision of Public Goods

ECO No. $90 / 8$

T. BRIANZA, L. PHLIPS and J.F. RICHARD

Futures Markets, Speculation and Monopoly Pricing

ECO No. 90/9

Anthony B. ATKINSON/ John

MICKLEWRIGHT

Unemployment Compensation and Labour Market Transition: A Critical Review

ECO No. $90 / 10$

Peter J. HAMMOND

The Role of Information in Economics

ECO No. 90/11

Nicos M. CHRISTODOULAKIS

Debt Dynamics in a Small Open Economy

ECO No. $90 / 12$

Stephen C. SMITH

On the Economic Rationale for Codetermination Law

ECO No. $90 / 13$

Elettra AGLIARDI

Learning by Doing and Market Structures

ECO No. 90/14

Peter J. HAMMOND

Intertemporal Objectives

ECO No. 90/15

Andrew EVANS/Stephen MARTIN

Socially Acceptable Distortion of Competition: EC Policy on State Aid 
ECO No. 90/16

Stephen MARTIN

Fringe Size and Cartel Stability

ECO No. 90/17

John MICKLEWRIGHT

Why Do Less Than a Quarter of the

Unemployed in Britain Receive Unemployment Insurance?

ECO No. 90/18

Mrudula A. PATEL

Optimal Life Cycle Saving

With Borrowing Constraints:

A Graphical Solution

ECO No. $90 / 19$

Peter J. HAMMOND

Money Metric Measures of Individual and Social

Welfare Allowing for Environmental

Externalities

ECO No. $90 / 20$

Louis PHLIPS/

Ronald M. HARSTAD

Oligopolistic Manipulation of Spot Markets and the Timing of Futures Market Speculation

ECO No. 90/21

Christian DUSTMANN

Earnings Adjustment of Temporary Migrants

ECO No. $90 / 22$

John MICKLEWRIGHT

The Reform of Unemployment Compensation:

Choices for East and West

ECO No. $90 / 23$

Joerg MAYER

U. S. Dollar and Deutschmark as Reserve Assets

ECO No. 90/24

Sheila MARNIE

Labour Market Reform in the USSR:

Fact or Fiction?

ECO No. 90/25

Peter JENSEN/

Niels WESTERGÅRD-NIELSEN

Temporary Layoffs and the Duration of

Unemployment: An Empirical Analysis

ECO No. $90 / 26$

Stephan L. KALB

Market-Led Approaches to European Monetary

Union in the Light of a Legal Restrictions

Theory of Money
ECO - No. 90/27

Robert J. WALDMANN

Implausible Results or Implausible Data?

Anomalies in the Construction of Value Added

Data and Implications for Estimates of Price-

Cost Markups

ECO No. $90 / 28$

Stephen MARTIN

Periodic Model Changes in Oligopoly

ECO No. $90 / 29$

Nicos CHRISTODOULAKIS/

Martin WEALE

Imperfect Competition in an Open Economy

$$
\text { * * * }
$$

ECO No. $91 / 30$

Steve ALPERN/Dennis J. SNOWER

Unemployment Through 'Learning From

Experience'

ECO No. $91 / 31$

David M. PRESCOTT/Thanasis STENGOS

Testing for Forecastible Nonlinear Dependence in Weekly Gold Rates of Return

ECO No. 91/32

Peter J. HAMMOND

Harsanyi's Utilitarian Theorem:

A Simpler Proof and Some Ethical

Connotations

ECO No. $91 / 33$

Anthony B. ATKINSON/

John MICKLEWRIGHT

Economic Transformation in Eastem Europe and the Distribution of Income

ECO No. 91/34

Svend ALBAEK

On Nash and Stackelberg Equilibria when Costs are Private Information

ECO No. 91/35

Stephen MARTIN

Private and Social Incentives

to Form R \& D Joint Ventures

ECO No. $91 / 36$

Louis PHLIPS

Manipulation of Crude Oil Futures

ECO No. 91/37

Xavier CALSAMIGLIA/Alan KIRMAN

A Unique Informationally Efficient and

Decentralized Mechanism With Fair Outcomes 
ECO No. 91/39
Peter J. HAMMOND
The Moral Status of Profits and Other Rewards:
A Perspective From Modern Welfare Economics

ECO No. $91 / 40$

Vincent BROUSSEAU/Alan KIRMAN

The Dynamics of Learning

in Mis-Specified Models

ECO No. 91/41

Robert James WALDMANN

Assessing the Relative Sizes of Industry- and

Nation Specific Shocks to Output

ECO No. $91 / 42$

Thorsten HENS/Alan KIRMAN/Louis PHLIPS

Exchange Rates and Oligopoly

ECO No. $91 / 43$

Peter J. HAMMOND

Consequentialist Decision Theory and

Utilitarian Ethics

ECO No. 91/44

Stephen MARTIN

Endogenous Firm Efficiency in a Cournot

Principal-Agent Model

ECO No. $91 / 45$

Svend ALBAEK

Upstream or Downstream Information Sharing?

ECO No. $91 / 46$

Thomas H. McCURDY/

Thanasis STENGOS

A Comparison of Risk-Premium Forecasts

Implied by Parametric Versus Nonparametric

Conditional Mean Estimators

ECO No. 91/47

Christian DUSTMANN

Temporary Migration and the Investment into

Human Capital

ECO No. 91/48

Jean-Daniel GUIGOU

Should Bankruptcy Proceedings be Initiated by a Mixed Creditor/Shareholder?

ECO No. 91/49

Nick VRIEND

Market-Making and Decentralized Trade
ECO No. $91 / 50$

Jeffrey L. COLES/Peter J. HAMMOND

Walrasian Equilibrium without Survival:

Existence, Efficiency, and Remedial Policy

ECO No. $91 / 51$

Frank CRITCHLEY/Paul MARRIOTT/

Mark SALMON

Preferred Point Geometry and Statistical Manifolds

ECO No. 91/52

Costanza TORRICELLI

The Influence of Futures on Spot Price

Volatility in a Model for a Storable Commodity

ECO No. $91 / 53$

Frank CRITCHLEY/Paul MARRIOTT/

Mark SALMON

Preferred Point Geometry and the Local

Differential Geometry of the Kullback-Leibler

Divergence

ECO No. 91/54

Peter MØLLGAARD/

Louis PHLIPS

Oil Futures and Strategic

Stocks at Sea

ECO No. 91/55

Christian DUSTMANN/

John MICKLEWRIGHT

Benefits, Incentives and Uncertainty

ECO No. $91 / 56$

John MICKLEWRIGHT/

Gianna GIANNELLI

Why do Women Married to Unemployed Men have Low Participation Rates?

ECO No. 91/57

John MICKLEWRIGHT

Income Support for the Unemployed

in Hungary

ECO No. 91/58

Fabio CANOVA

Detrending and Business

Cycle Facts

ECO No. 91/59

Fabio CANOVA/

Jane MARRINAN

Reconciling the Term Structure of Interest Rates with the Consumption Based ICAP Model 


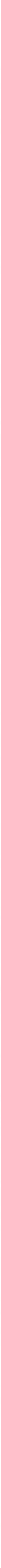


